WSRC-RP $--90-820$

DE9 I 006524

\title{
MEASURING THE EFFICACY OF A ROOT BIOBARRIER WITH X-RAY
} COMPUTED TOMOGRAPHY (U)

E. W. Tollner and C.E. Murphy Jr.

Publication Date: August 16, 1990

Final Report: Subcontract \#867553

From:

The University of Georgia

Department of Agricultural Engineering

Griffin, GA

To:

Westingtouse Savannah River Company

Savannah River Site

Aiken, SC 29808

PREPARED FOR THE U.S. DEPARTMENT OF ENERGY UNDER CONTRACT DE-AC09.89SR18035 


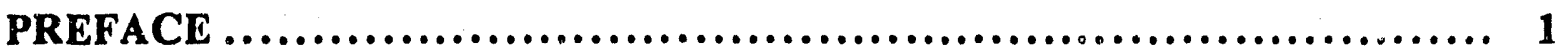

CHAPTER I

FACTORS AFFECTING SOIL X-RAY ABSORPTION

COEFFICIENTS WITH COMPUTER TOMOGRAPHY $\ldots \ldots \ldots \ldots \ldots \ldots, 3$

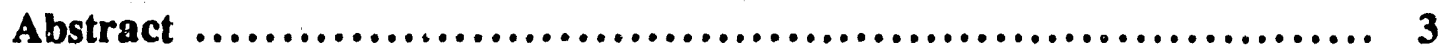

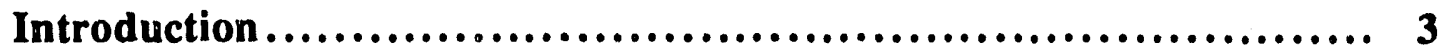

Objectives...$\ldots \ldots \ldots \ldots \ldots \ldots \ldots \ldots \ldots \ldots \ldots \ldots \ldots \ldots \ldots \ldots \ldots \ldots \ldots \ldots \ldots \ldots$

Theoretical Factors Affecting X-Ray Absorption .................. 4

Materials and Methods $\ldots \ldots \ldots \ldots \ldots \ldots \ldots \ldots \ldots \ldots \ldots \ldots \ldots \ldots \ldots \ldots \ldots \ldots, 6$

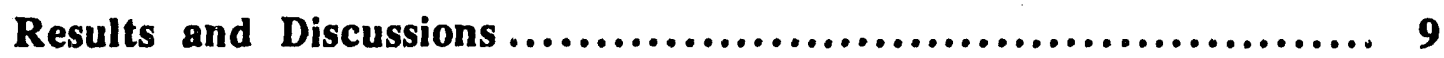

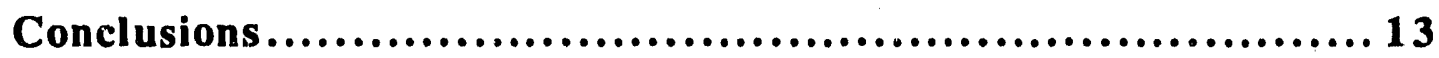

Acknowledgement $\ldots \ldots \ldots \ldots \ldots \ldots \ldots \ldots \ldots \ldots \ldots \ldots \ldots \ldots \ldots \ldots \ldots \ldots \ldots \ldots$

References $\ldots \ldots \ldots \ldots \ldots \ldots \ldots \ldots \ldots \ldots \ldots \ldots \ldots \ldots \ldots \ldots \ldots \ldots \ldots \ldots \ldots$

\section{CHAPTER II}

INTERPRETING THE PIXEL STANDARD DEVIATION

STATISTIC FROM AN X-RAY TOMOGRAPHIC SCANNER....... 16

Abstract $\ldots \ldots \ldots \ldots \ldots \ldots \ldots \ldots \ldots \ldots \ldots \ldots \ldots \ldots \ldots \ldots \ldots \ldots \ldots \ldots \ldots \ldots \ldots \ldots$

Introduction $\ldots \ldots \ldots \ldots \ldots \ldots \ldots \ldots \ldots \ldots \ldots \ldots \ldots \ldots \ldots \ldots \ldots \ldots \ldots \ldots \ldots \ldots$

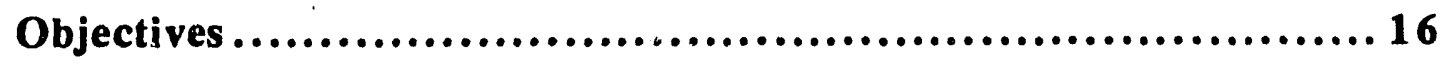

Model Derivation..$\ldots \ldots \ldots \ldots \ldots \ldots \ldots \ldots \ldots \ldots \ldots \ldots \ldots \ldots \ldots \ldots \ldots$

Materials and Methods..$\ldots \ldots \ldots \ldots \ldots \ldots \ldots \ldots \ldots \ldots \ldots \ldots \ldots \ldots$

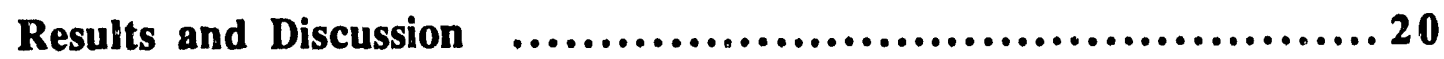

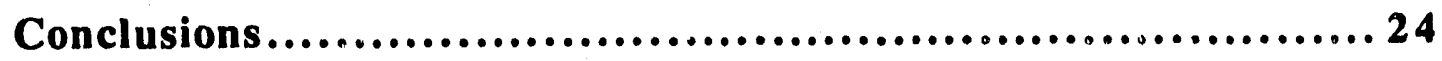

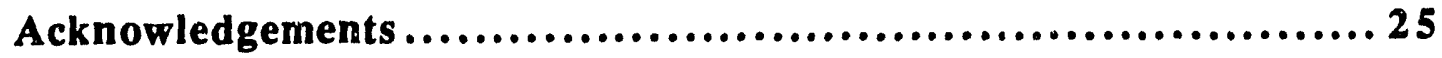

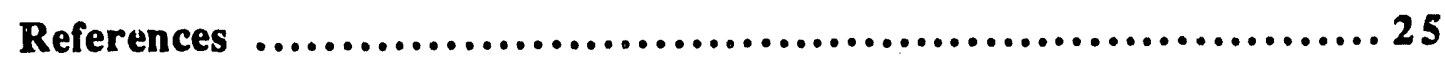

-iii- 
CHAPTER III

TECHNIQUES AND APPROACHES FOR DOCUMENTING PLANT ROOT DEVELOPMENT WITH X-RAY COMPUTED

TOMOG R A PHY Y $\ldots \ldots \ldots \ldots \ldots \ldots \ldots \ldots \ldots \ldots \ldots \ldots \ldots \ldots \ldots \ldots \ldots \ldots \ldots \ldots \ldots \ldots \ldots$

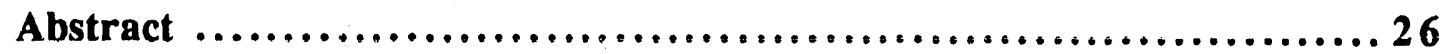

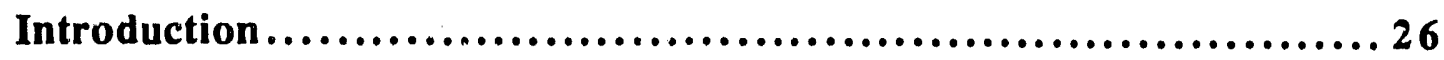

Objective $\ldots \ldots \ldots \ldots \ldots \ldots \ldots \ldots \ldots \ldots \ldots \ldots \ldots \ldots \ldots \ldots \ldots \ldots \ldots \ldots \ldots \ldots \ldots, \ldots \ldots \ldots$

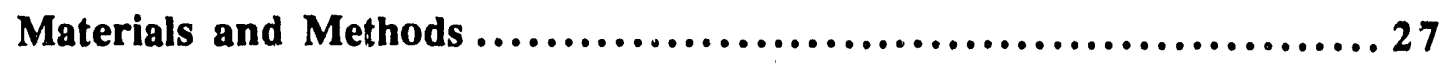

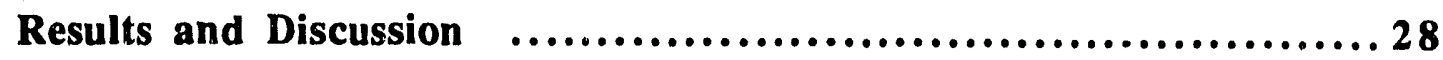

Mean Absorption .................................... 8

Pixel Standard Deviation and

Absorption Histograms .............................

Conclusions ...................................................... 33

Acknowledgements..$\ldots \ldots \ldots \ldots \ldots \ldots \ldots \ldots \ldots \ldots \ldots \ldots \ldots \ldots \ldots \ldots \ldots \ldots \ldots$

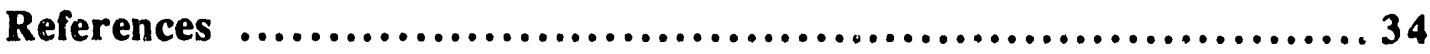




\section{CHAPTER I}

1 Photograph of Soil Container Being Inserted into the Support Jig, with the Scanner Gantry in the Background .................... 8

2 X-Ray CT Image of the Cecil Surface Soil. The Light Areas Represent High Compaction and/or Soil Water. The Horizontal Layers Represent Zones Formed During Container Filling

\section{CHAPTER II}

1 Photograph of Fixture for Supporting Water-Submerged

Wood and Plexiglass Media in the Scanner Gantry $\ldots . . . \ldots \ldots \ldots \ldots \ldots \ldots 18$

2 Photograph of X-Ray CT Image of Plexiglass in Water Showing Pore-Background Contrast.................................. 20

3 Plot of Pixel Histogram from Plexiglass-Air Study ................. 21

4 Calculated (from Eq. (2)) vs. Observed (CT Scanner) Pixel Standard Deviation Values.......................................... 22

5a Calculated (from Eq.(2, 2a)) vs. Actual Pixel Numbers with Plexiglass and Wood Background with Air and Water Pore Space...... 23

5b Calculated (from Eq. (2a, 3)) vs. Actual Pixel Numbers with Plexiglass and Wood Background with Air and Water Pore Space...... 2,3

5c Calculated (from Eq. $(2,3)$ ) vs. Actual Pixel Numbers with Plexiglass and Wood Background with Air and Water Pore Space...... 23

5d Calculated (Histogram) vs. Actual Pixel Numbers with Plexiglass and Wood Background with Air and Water Pore Space 


\section{CHAPTER III}

1a Plot Showing Average for Three Reps of Ront Leugth

Density vs. Depth at Day 84 in Bahiagrass................................ 29

1b Plot Showing Average for Three Reps of Root Length

Density vs. Depth at Day 84 in Soybean ......................... 29

2 Photograph of CT Scan of Soybean at Day 57..................... 29

3 Plots of Predicted Volumetric Water Content vs. Time for the

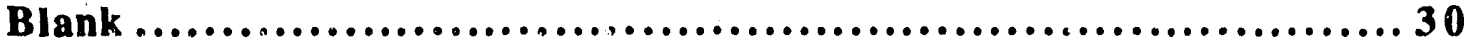

4 Plots of Predicted Volumetric Water Content vs. Time for the

Bahiagrass .......................................................... 31

5 Plots of Predicted Volumetric Water Content vs. Time for the

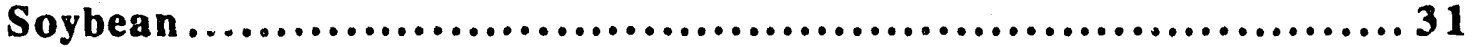

6 a Schematic Diagram of a Pixel Histogram Showing Several

Variables which were Defined to Characterize Histogram

Features. X-Ray Absorption Values Less than the Range

Minimum (RNGMI) or Greater than the Range Maximum

(RNGMX) are Designated as Minimum and Maximum

Outliers............................................................... 32

6b Actual Pixel Histogram for Lakeland Sand, Soybeans,

Depth 1, Day 57 


\section{CHAPTER 1}

1 List of Five Selected Test Soils, Particle Analysis and Other Pertinent Characteristics....................................... 7

2 Drying Oven Time-Temperature Schedule for Achieving Eight Moisture Contents ............................................ 9

3 Analysis of Variance for Mean Absorption, Density, and Water Content, with Five Test Soils ....................................... 10

4 Regression Analysis of the Second Order - Expanded Model for the Five Test Soils ........................................ 11

5 Regression Analysis of the Linear Model for the Five Test Soils ............................................................. 12

6 Regression Analysis Using the Linear Model. Intercepts and the Water Coefficient Forced to the Standard Measured Value of $0.191 \mathrm{~cm}^{-1}$

\section{CHAPTER II}

1 Selected Results From the Controlled Media Experiment ............... 19

\section{CHAPTER III}

1 Scanning Locations and Root Barrier Placement............................ 28 


\section{PREFACE}

This document is the final report of a cooperative research project between the Department of Agricultural Engineering, The University of Georgia, Georgia Experiment Station, Griffin, GA and the Environmental Science Section, Savannah River Laboratory, Westinghouse Savannah River Company, Aiken, SC. Funding was through the contract between the Westinghouse Savannah River Company and the U.S. Department of Energy under contract DE-AC0989SR18035. This document is the final report under this contract.

$\mathrm{X}$-ray tomographic scanning can provide quantitative outputs of root growth or activity. The scanner measures mean absorption of approximately $1 \mathrm{~mm} \times 1 \mathrm{~mm} \times 13 \mathrm{~mm}$ regions known as pixels or voxels. The scanner allows for repeated measurement of a plant over time. The average absorpjion, absorption pixel standard deviation, and statistics derived from the pixel absorption histogram appear to be indicative of root function. This conclusion is based on changes which occurred over time in experiments with soybeans and Bahiagrass with and without a rooting barrier.

X-ray Computer Tomngraphy (CT) is a new tool for the study of plant-soil relations. As such, considerable testing was undertaken to ascertain factors common in soil-plant systems which affect CT scanner outputs, particularly the mean and standard deviation. Statistics were identified which may be indicative of root presence in certain conditions.

The body of the report consists of three manuscripts. The first two reports describe findings related to (1) respective mean absorption, and (2) pixel standard deviation statistics An additional manuscript (3) describes how photographs of images, selected statistics from the pixel histogram, and changes in mean absorption (related to water content changes) can be indicative of root presence.

The x-ray absorption, soil absorption, and soil water calibration study (manuscript l) lead to the following conclusions:

1. A linear relationship among the absorption coefficients for solids and liquid portions enables coefficients for each phase to be measured independently, greatly facilitating calibration.

2. The standard measured absorption value for water of $0.191 \mathrm{~cm}^{-1}$ was duplicated, implying that one need not determine this coefficient for each soil.

3. Additional empirical relationships and/or theory is needed for predicting the absorption coefficient for solids based on known values for water. It is felt that the theory would provide estimates of the solids' absorption coefficient relative to water. Further studies are needed to factor in the photomultiplier gain settings so as to better predict the absorption of solids relative to water. Separating the wavelength shift effect from the photomultiplier gain effect appears to be difficult.

4. For all soils tested, except Wilcox clay, the predicted soil density term was constant within $5 \%$ when a fixed water absorption coefficient was used in the calculates. 
A model for predicting the overall pixel standard deviation was developed by assuming the histogram to be comprised of two (or three) distributions having the same underlying standard deviation. This assumption proved to hold reasonably well. The specific conclusions drawn from the model were as follows:

1. The standard deviations for pore media (air, water) absorption were accurately predicted, except when pore size was small relative to pixel size or when the background media more closely approximated the pore media in terms of $\mathrm{x}$-ray absorption.

2. Pixels representing fores were predicted to within $20 \%$ using the standard deviation equation (2) coupled with the equation ( $2 a$ ) for total pixels or the nean absorption equation (3).

3. The technique can be used for rudimentary image analysis when two or possibly three distributions comprise the pixel histogram.

In a plant root development study involving the growth of soybean and Bahiagrass species in Lakeland sand columns (with and without chemical rooting barrier), $x$-ray CT provided three types of output indicative of rooting activity. The first of these indicators was the obtaining of visible images of roots. However, the appearance of visible features probably lags the actual presence of plant root mass. The other two indicators were the effect on surrounding soil water content and selected statistics determined from pixel histograms.

$\mathrm{X}$-ray CT confirmed in a nondestructive manner that the rooting barrier was effective in the case of soybeans and Bahiagrass based on obvious changes in water withdrawal patterns. Histogram symmetry also appeared to change over time.

The work reported in this study has indicated the availability of further research that will lead to improvements in the use of X-ray CT scanning in plant root studies. Such research is listed as follows:

1. Collect additional data using destructive testing with pots, in order to have data sets that will allow for correlation of scanner outputs with actual measured root mass.

2. Using approaches based on Richards' equation, attempt to develop a procedure for determining an optimal solution for root length, given a differential, water content vs. depth function, and soil hydraulic properties.

3. Further explore approaches to apply the standard deviation statistic to roots and voids in soil systems. 


\title{
I. FACTORS AFFECTING SOIL X-RAY ABSORPTION COEFFICIENTS WITH COMPUTER TOMOGRAPHY
}

\author{
E.W. Tollner and Charles Murphy
}

\begin{abstract}
$\mathrm{X}$-ray computed tomography is a useful tool for investigating soil physical properties nondestructively. There is a need to develop proper calibration relationships between soil properties and the $\mathrm{x}$-ray absorption coefficient. The objective of this work was to evaluate soil factors affecting the $x$-ray absorption coefficient. Based on a theoretical analysis, experimental data from five soils and on results of several other investigators, it was concluded that for many applications, one calibration relationship is applicable to a wide range of soils. The montmorillinitic clay used in the study required special handling due to the extreme shrinkage of this soil upon drying. Knowledge of chemical composition enables approximations but not exact predictions of the $\mathrm{x}$-ray absorption coefficient. The results suggested some reasonable alternative to exhaustive calibration for each anticipated soil condition.
\end{abstract}

\section{Introduction}

$\mathrm{X}$-ray compuied tomography $(\mathrm{CT})$ is proving increasingly useful for measuring soil physical properties nondestructively. Mo t quantitative applications of CT presume that one has calibration data for soils spanning the conditons of interest. Petrovic et al. (1982), Hainsworth and Aylmore (1986), Crestana et al. (1985), Anderson et al. (1988), and Tollner and Verma (1989) have all shown $\mathrm{x}$-ray CT to be an effective way to measure mean $\mathrm{x}$-ray absorption. They successfully related mean $\mathbf{x}$-ray absorption to density and/or soil-water content.

Considerable time and expense are involved in defining the relationship between mean $\mathrm{x}$-ray absorption and soil properties for each soil. Based on Anderson et al. (1988), there is reason to believe that relationships may be similar for a wide range of soils. If commonality over a range of soil types could be proven true, then measurements with CT systems would potentially not require calibration for each soil condition.

The proposition that all soils could be adequately described by one calibration relationship could be investigated by (1) doing an exhaustive test on numerous soils, or by (2) doing a theoretical analysis of factors affecting $\mathbf{X}$-ray radiation absorption. A combination of these options was used and results were compared with results from the literature.

\section{Objectives}

The objectives of this study were to:

1. Develop a theoretical relationship between mean $\mathrm{x}$-ray absorption coefficients and $\mathrm{x}$-ray energy levels, soil chemical attributes, soil physical characteristics, and soil moisture.

2. Develop empirical relationships between mean $\mathbf{x}$-ray absorpticn and soil physical properties, and soil moisture for several soils, and finally, to compare them to the theoretical relationships of Objective 1.

Respectively, Associate Professor, Department of Agricultural Engineering, The University of Georgia, Georgia Experiment Station, Griffin, GA 30223-1797; and Ecologist, Westinghouse Savannah River Corporation, Aiken, South Carolina. 


\section{Theoretical Factors Affecting X-Ray Absorption}

Garrett and Lenker (1984) present the fundamental of $\mathrm{x}$-ray absorption for some agricultural applications with emphasis on low absorbers. This development restates and expands the development as relevant for tomographic scanners. X-ray tomography derives its success in medical applications from mapping the $\mathrm{x}$-ray absorption coefficient $(\mathrm{m})$ over user selected regions within solid objects by passing many $\mathrm{x}$-ray projections over a variety of angles and positions through the region (Herman (1980) and Tollner et al. (1989). Beer's Law (Eq. (1)) has been used to describe the $\mathrm{X}$-ray absorption process in medical CT applications.

$$
\mathrm{I}=\mathrm{I}_{0} \exp (-\mu \mathrm{L}) \text {, }
$$

where

$$
\begin{aligned}
\mathrm{I}= & \text { x-ray photon intensity striking the detectors, } \\
\mathrm{I}_{0}= & \text { initial x-ray photon intensity, } \\
\mu= & \text { the } x \text {-ray coefficient }(\mathrm{L}-1), \\
\mathrm{L}= & \text { the projection length, which is the diamerer of the scanned plane. } \\
& \text { (This diameter is determined by hardware and to a limited extent by } \\
& \text { software.) }
\end{aligned}
$$

The coefficient $\mu$ is a mass average for the solids plus water within each image pixel $\left(L_{r x} W_{r}\right)$. [(Actually, the coefficient $m$ is a mass average of material in a voxel $\left(L_{r x} W_{r x} D_{r}\right)$, where $L_{r}$ and $W_{r}$ are the length and width viewed on the viewing console. The depth dimension $\left(D_{r}\right)$ arises from the finite X-ray beam thickness as set by the collimator (Tollner et al. 1989)]. McCullovgh (1975) showed that in medical applications the absorption coefficient could be expanded as follows:

$$
\mu=\mu_{s} f_{s}+\mu_{w} f_{w}
$$

where

$$
\begin{aligned}
& \mu_{s}=\text { absorption coefficient for pure solids }\left(L^{-1}\right) \\
& \mu_{w}=\text { absorption coefficient for water }\left(L^{-1}\right) \\
& f_{S}=\text { volume fraction of pure solids in the pixel, } \\
& f_{W}=\text { volume fraction of pure water in the pixel. }
\end{aligned}
$$

In this paper, $\mu_{s}$ and $f_{S}$ will represent the soil solids.

Understanding the x-ray absorption process is required to properly exploit the CT systems and to properly initiate efforts to design customized systems for soil studies. The applicability of Beer's Law implies a monochromatic $x$-ray source and one predominant mechanism of $x$-ray absorption. One check on the validity of Beer's Law includes p-ediction of the $x$-ray absorption coefficient for water in soils and comparing it with the absorption coefficient of pure water.

For soil studies, Eo (2a) can be written as follows:

$$
\mu=\mu_{\mathrm{s}}\left(\mathrm{P}_{\mathrm{DB}} / \mathrm{P}_{\mathrm{SG}}\right)+\mu_{\mathrm{w}} \theta_{\mathrm{w}},
$$

where

$$
\begin{aligned}
& \text { PDB }=\text { dry bulk density }\left(\mathrm{Mg} / \mathrm{m}^{3}\right) \\
& \text { PSG }_{\text {S }} \text { specific density of soil particles }\left(\mathrm{Mg} / \mathrm{m}^{3}\right) \\
& \theta_{\mathrm{w}}=\text { volumetric water content. }
\end{aligned}
$$

A substantial body of knowledge exists on processes affecting abscrption of monochromatic $\mathrm{x}$-rays. Based on Richards et al. (1960), x-ray absorption can be described as 


$$
\mu=\mathrm{k} \lambda 3 \mathrm{Z}^{3} \mathrm{PSG}
$$

where

$\mathbf{k}=$ empirical constant of proportionality,

$\lambda=$ monochromatic $x$-ray wavelength $(\mathrm{m})$,

$\mathrm{Z}=$ effective atomic number (electron density).

Eq. (3) was developed using monochromatic x-rays and is valid at energy levels where one xray absorption mechanism predominates. The linear constant in Eq. (3) assumes that $\mathrm{x}$-ray wavelengths are such that no absorption edges are present (Richards et al., 1960; Weast, 1969). Absorption edges are specific wavelengths where jump discontinuities occur in the absorption vs. the wavelength relationship.

Richards et al. (1960) state that the minimum possible wavelength can be estimated from excitation energy as follows:

$$
\lambda_{\min }=12,396 / \mathrm{V}
$$

where

$$
\begin{aligned}
\lambda_{\min } & =\text { minimum possible wavelength }(10-10 \mathrm{~m}) \\
\mathrm{V} & =\text { excitation voltage }(\mathrm{V}) .
\end{aligned}
$$

Typical CT systems operate over a range of $100-140 \mathrm{KV}$ excitation; hence, minimum wavelengths may range from 0.09-0.12 $\times 10-10 \mathrm{~m}$. Minimum absorptio.. edges, which occur for the predominant elements in soils, are greater than $0.09 \times 10^{-10} \mathrm{~m}$ (Weast, 1969). CT systems are polychromatic with a spectrum of wavelengths ranging over one or two orders of magnitude in wavelength greater than the minimum possible wavelength predicted by Eq. (4) (Anon., 1986).

The distribution before passing through the scanned object is typically normal with most photons having wavelengths near the minimum absorption edges for the target material in the $x$-ray tube. Older CT scanners typically use tungsten (minimum absorption edge of $0.17 \times 10^{-10} \mathrm{~m}$ ) targets with aluminum filtering (minimum absorption edge of $4.2 \times 10^{-10} \mathrm{~m}$ ). The typical energy levels used along with the tungsten target and aluminum filter would result in an energy spectrum which for the most part is above the absorption minimums fo: common soil minerals (Weast, 1969); however, soil minerals can have absorption edges near the edge for the aluminum filter.

Photoelectric x-ray absorption predominates up to approximately 100-200 KV (Richards et al., 1960). Transitions to other $x$-ray absorption mechanisms (Compton scattering and positronelectron pair production) occur at higher energy levels (Richards et al., 1960). The excitation range available on CT systems would appear to largely avoid absorption edges and at the same time maintain one preduminant absorption mechanism (photoelectric absorption).

Dense materials selectively absorb lower energy $x$-rays in polychromatic $x$-ray sources; thus, the "average" wavelength entering the scanned plane $\left(\mathrm{L}_{0}\right.$ in Eq. $\left.(\mathrm{I})\right)$ is somewhat longer than the average wavelength exiting the scanned plane and striking the detectors (I). This is commonly known as beam hardening (Herman, 1980). Anon. (1986) presents data showing that a $40 \mathrm{~cm}$ water body caused an effective shift in wavelength from $0.21 \times 10^{-10} \mathrm{~m}$ to $0.125 \times 10^{-10} \mathrm{~m}$ with a Siemens system having a copper-tungsten target. The distribution would be even more skewed toward the minimum possible wavelength with soil. The beam hardening is of greater concern when used in soil, because the soil is at least as great an absorber as the filtering element on first and second generation CT systems. Thus with CT scarners, there is basically one mode of absorption, with energy levels avoiding most absorption edges. However, beam hardening effects are to be expected. 
Using Eq. (2b) and Eq. (3), a comprehensive equation for relating average $x$-ray absorption to soil physical properties, soil chemical characteristics, and the soil water can be written as

$$
\mu=k \lambda_{s}{ }^{3} Z_{s}{ }^{3} P_{S G}\left(P_{D B} / P_{S G}\right)+k \lambda_{w} 3 Z_{w} 3 \theta_{w} \text {, }
$$

where $\quad \lambda_{\mathrm{s}}=$ effective $\mathrm{x}$-ray wavelength for soil solids $(10-10 \mathrm{~m})$,

$\lambda_{w}=$ effective $x$-ray wavelength for water $(10-10 \mathrm{~m})$,

$Z_{\mathbf{s}}=$ effective atomic number of soil,

$\mathrm{Z}_{\mathrm{w}}=$ effective atomic number of water.

In Eq. (5), the density of water is assumed to be $1.0 \mathrm{Mg} / \mathrm{m}^{3}$.

Eq. (3) can be used to develop a basis for relating $k \lambda_{s} Z_{s}{ }^{3}\left(\mu_{s}\right)$ to $k \lambda_{w} Z_{w}{ }^{3}\left(\mu_{w}\right)$. In effect, the $\mu_{w}$ is known to be $0.191 \mathrm{~cm}^{-1}$ under conditions used in our study (Hainsworth and Aylmore, 1986). Since, in Eq. (3), the proportionality constant is similar, one could define a ratio between the soil and water absorption coefficient as follows:

$$
\mu_{s} / \mu_{w}=\operatorname{PSG}\left(\lambda_{s}{ }^{3} Z_{s}^{3}\right) /\left(\lambda_{w^{3}} Z_{w^{3}}\right)
$$

where $\mu_{s}$ and $\mu_{w}$ represent absorption of pure soil and water, respectively; $\lambda_{s}$ and $\lambda_{w^{\prime}}$ represent the resulting wavelength with soil and water, respectively; and with $Z_{s}$ and $Z_{w}$ as defined previously. The effective atomic number of the water molecule $\left(\mathrm{H}_{2} \mathrm{O}\right)$ was $6.6=(8 \times 8 / 10+1 \times 2 / 10)$. The effective atomic number of soil was calculated by computing the ratio of element atoms to total atoms in the mineral, multiplying the ratio by the atomic number of the element and summing it over all the constituent elements. Using structural formulas in Baver et al. (1972) and Dixon and Weed (1977), effective atomic number values were 10.5 for $1: 1$ clays, 10.7 for $2: 1$ clays (excluding water between the layers), 10.85 for sand $\left(\mathrm{SiO}_{2}\right), 9.76$ for vermiculite, 13.04 for illite, 10.6 for aluminum oxide, and 18.7 for iron oxide. Thus, many soils will have similar absorption coefficients. The two exceptions may be soils in which illite minerals predominate or soils with high iron contents.

Eq. (6) is difficult to apply with CT scanners. CT scanners do not measure absnlute absorption magnitudes during the course of a scan. Gains of the photoelectric detectors are preset by the operator to stay within operational parameters and these settings are not factored into the absorption calculation. Discrepancies in observed and expected values would be expected to be largest with dense materials well removed from the air and water calibration references. Also, elements with higher atomic numbers would cause shorter, effective wavelengths due to beam hardening. This is particularly true where the soil body is elementally similar to the filtering element (aluminum). However, Eq. (6) can be useful for estimating relative magnitude in the solids $x$-ray absorption coefficient. For exanple, if one assumes no differences in detector gain or no shift in effective wavelength, the soil absorption coefficient would be approximately $2.65 x$ $(10.8 / 6.6)^{3}$, which is 11.6 times that of water. The actual coefficient must be investigated experimentally.

\section{Materials and Methods}

Five soils were selected to represent a broad range of common soil mineralogies. Selected sampling details and physical properties are tabulated in Table 1. Textural analyses and particle density were run following procedures set forth in Klute (1986) and iron was analyzed following Shuman (1979). Procedures were developed to achieve a reasonably repeatable range in both dry density and water content. 
Table 1. List of the Five Selecied Test Soils, Particle Analysis and Other Fertinent Characteristics

\begin{tabular}{|c|c|c|c|c|c|c|c|c|}
\hline $\begin{array}{c}\text { Scil Type } \\
\text { (sampling depth) } \\
\text { (location) }\end{array}$ & $\begin{array}{l}\text { Taxon } \\
\text { Group }\end{array}$ & $\begin{array}{l}\text { Sand } \\
(\%)\end{array}$ & $\begin{array}{l}\text { Texture } \\
\text { Silt } \\
(\%)\end{array}$ & Clay & $\begin{array}{c}\text { Dry Bulk } \\
\text { Density Range } \\
\left(\mathrm{Mg} / \mathrm{m}^{3}\right)\end{array}$ & $\begin{array}{l}\text { Vul. Water } \\
\text { Content } \\
\text { Maximum }\end{array}$ & $\begin{array}{l}\text { Particle } \\
\text { Density } / \\
\left(\mathrm{Mg} / \mathrm{m}^{3}\right)\end{array}$ & $\begin{array}{l}\text { Total } \\
\text { Iron } \\
(\%)\end{array}$ \\
\hline $\begin{array}{l}\text { Lakeland } \\
\text { Sand } \\
(0-150 \mathrm{~mm}) \\
\text { (Tifion) }\end{array}$ & $\begin{array}{l}\text { Typic } \\
\text { Qurarsipsam- } \\
\text { ments }\end{array}$ & 91 & 6 & 3 & $1.29-1.60$ & 19.8 & 2.65 & 0.19 \\
\hline $\begin{array}{l}\text { Cecil Sandy } \\
\text { Loam I } \\
\text { (0-150 mm) } \\
\text { (Watkinsville) }\end{array}$ & $\begin{array}{l}\text { Typic } \\
\text { Hapludults }\end{array}$ & 84 & 11 & 5 & $1.10 \cdot 1.70$ & 22.02 & 2.65 & 1.04 \\
\hline $\begin{array}{l}\text { Cecil Sandy } \\
\text { Loam II } \\
\text { (150-300 mm) } \\
\text { (Watkinsville) }\end{array}$ & $\begin{array}{l}\text { Typic } \\
\text { Hapludults }\end{array}$ & 55 & 15 & 32 & $1.03-1.76$ & 24.03 & 2.65 & 2.19 \\
\hline $\begin{array}{l}\text { Troup Sand } \\
\text { (0-150 mm) } \\
\text { (Metter) }\end{array}$ & $\begin{array}{l}\text { Grossarenic } \\
\text { Paleadults }\end{array}$ & 93 & 5 & 2 & $1.53-1.80$ & 19.4 & 2.65 & 0.65 \\
\hline Wilcox Clay $2 /$ & $\begin{array}{l}\text { Vertic } \\
\text { Hapludults }\end{array}$ & 5.5 & 28 & 66 & $0.85-1.02$ & 53.7 & 2.65 & 4.55 \\
\hline
\end{tabular}

1V Particle densities besod on inessurements of the wuthors (1.5\%)

$2 /$ Provided by Dr. Raxdy/ Raper, USDA-NSDL, Aubarm, AL.

Sampling depth and laciation unknown.

Each soil was sieved with a $2 \mathrm{~mm}$ sieve in an air dry state and rewet by misting under an atomizing nozzle. Soils were wet such that they could be passed through a $4 \mathrm{~mm}$ sieve for purposes of artifically providing some structure. The maximum moisture content was found by trial and error and as shown in Table 1. Moistened soils were placed in $1.0 \mathrm{~L}$ wide-mouth Nalgene containers using three levels of compaction. The soil containers were cylindrical, which facilitated the achievement of reasonably $i$ iform compsction levels throughout the container.

Compaction levels were achieved with the following technique:

(1) Using a specially constucted drop hammer, one blow was applied to the container after filling with loose soil (level 1);

(2) Filling the container half full of soil, applying three blows, refilling, and applying three additional blows (level 2); 
(3) Filling the container to a depth of $3 \mathrm{~mm}$, applying five blows, and continuing this process until the container was full with compacted soil (level 3 ).

The drop hammer weighed $2.0 \mathrm{~kg}$ and the mass impacted a $13 \mathrm{~mm}$ (thick) plywood disk which was $1.05 \mathrm{mrn}$ in diumeter. The drop hammer mass fell $30 \mathrm{~cm}$ for each blow and the plywood disk fit within the $1.0 \mathrm{~L}$ Nalgene container. The range of dry bulk densitier achieved by the compaction levels is tabulated in Table 1.

Containers were weighed and then placed in an EMI 5005 x-ray CT scanner for x-ray absorption measurements. Containers were 'aced in a wooden frame and scanned with the maximum rectangular cross-sectional area in the scanned plane. Duplicate scans were made at each location, resulting in two scans per container at each scanning event. Scanner parameters were set at a $120 \mathrm{KV}$ energy level, $890 \mathrm{ma}$-s photon intensity, and $13 \mathrm{~mm}$ collimation. The $\mathrm{x}$-ray target was tungsten. A photograph of a sample container in the container support fixture is shown in Figure 1.

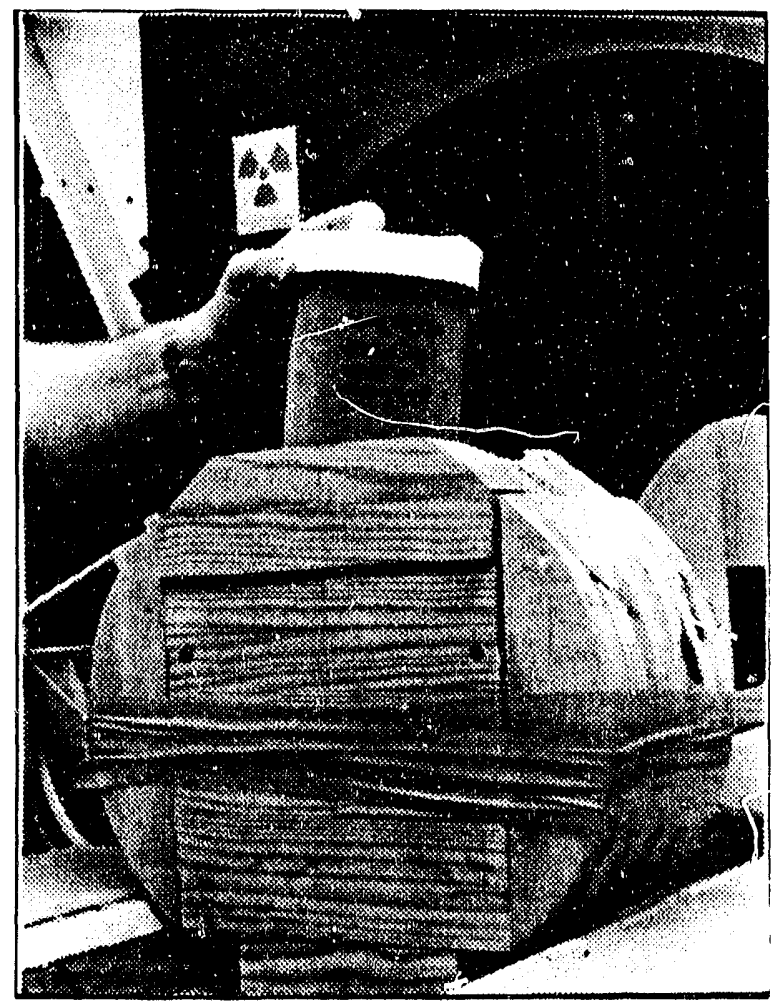

Figure 1. Photograph of a Soil Container Being Inserted into the Support Jig, with the Scanner Gantry in the Background.

After scanning, samples were placed in a drying oven in accordance with the temperature/time schedule shown in Table 2. The drying schedule was arrived at by trial and error to get a grod range of water contents. Containers were then weighed and rescanned as described above for each ncrement in the drying schedule. The entire experiment was repeated to have a total of two data sets for each soil. 
Table 2. Drying Oven Time-Temperature Schedule For Achieving Eight Moisture Contents
1. Wet
- 2. 16 Hours at $40^{\circ} \mathrm{C}$
-3. 16 Hours at $40^{\circ} \mathrm{C}$
- 4. 16 Hours at $40^{\circ} \mathrm{C}$
5. 16 Hours at $40^{\circ} \mathrm{C}$
6. 16 Hours at $55^{\circ} \mathrm{C}$
7. 26 Hours at $60 \%$
8. 72 Hours at $105^{\circ} \mathrm{C}$

- At steps 2, 3, 4 on Lakeland and Jenkins soils, lidwas set on loosely to slow the drying process.

All data were then analyzed in accordance with a randomized complete block design (SAS, 1985). General linear model procedures were used for preliminary analysis to test for trends within containers. Representative averages for each container at each drying time were then analyzed using regression procedures available in SAS (1985).

\section{Results and Discussion}

A typical image is shown in Figure 2.

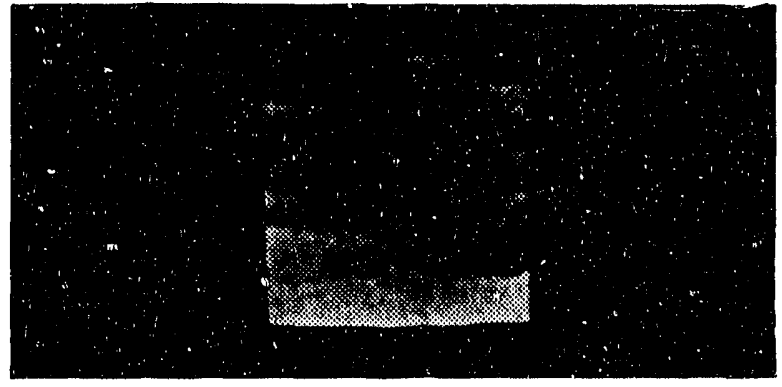

Figure 2. X-ray CT image of the Cecil Surface Soil. The light Areas Represent High Compaction and/or Soil Water. The Horizontal Layers Represent Zones Formed During Container Filling.

Using scanner software options, the mean absorption of the image portion representing the soil was obtained. Absorption values were also obtained for three non-overlapping subregions representing the top, middle and bottom zones of each image. X-ray absorption measurements were converted from Hounsfield units to absolute absorption $\left(\mathrm{cm}^{-1}\right)$ using the procedures in Tollner et al. (1989). The equations presented for absolute absorption in Tollner et al. (1989) assumed that the scanners could measure Hounsfield units down to (-)1000. The EMI 5005 measures absorption down to (-)500 Hounsfield units. Ve thus modified the Tollner $e_{i}$ sl. (1989) relationship as follows: 


$$
\mu=[(\mathrm{H}+500) / 500] \times 0.191,
$$

where $\quad \mathrm{H}=$ mean $\mathrm{x}$-ray absorption in Hounsfield units.

A summary of the analysis of variance on mean absorption, density, and volumetric water is listed in Table 3. The effect of replications were not significant at the 5\% level for mean absorption, but the effects of density and volumetric water were significant. Soil was significant at the 0.1 level for absorption density and volumetric water content. Sampling position was significant at the $1 \%$ level for mean absorption. This effectively means that the sample preparation technique was not successful in achieving uniform density across the soil container, and the significarce of the sampling position by soil interaction at the 5\% level implied that different soils compacted differently. Sampling position was not monitored for density and for water content because density and water were measured on a whole container basis. With mean absorption and volumetric water content, drying time was significant at the $1 \%$ level. The Wilcox clay did exhibit significant shrinkage and swelling typical of soils of 2:1 clay mineralogy. The assumption of zero shrinkage over drying was largely met with all soils except the Wilcox clay.

Table 3. Analysis of Variance for Mean Absorption, Density, and Water Content with the Five Test Soils

Variable Analyzed

Source

Significance Level

Mean Absorption

Rep

Soil

Sampling Position

Dry Time

Sampling $x$ Soil

Soil $x$ Dry Time

Sample $x$ Dry Time

NS

***

***

$*$

4

$* *$

NS

Density 2/

Rep

Soil

Dry Time

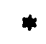

Soil x Dry Time

NS

Rep

Soil

Dry Time

Soil $x$ Dry Time

1 NS Not significant

** Significant at $1 \%$ level

* Significant at $5 \%$ level

21 Sampling position means not included because sampling position was calculated on a whole-container basis. 
A regression analysis with linear and quadratic density and water terms was run for each test soil and the results are summarized in Table 4. In most cases, the density squared and water terms were not significant at the $5 \%$ level. All soils except the Wilcox clay had high $\mathrm{R}^{2}$ values. The Wilcox clay exhibited substantially different behavior from the other soils. With this soil, absorption was related to water content and water content squared, but not to density. This result may be due to the assumption of constant dry density over the experiment duration, which was clearly not the case with the Wilcox clay. The large cracks which occurred during the course of the experiment indicate shrinkage in this soil. The compaction procedures did not result in substantial shifts in dry density with the Wilcox soils (Table 1). However, there was much shrinkage on drying.

Table 4. Regression Analysis of the Second Order - Expanded Model For the Five Test Soils

\begin{tabular}{|c|c|c|c|c|c|c|c|}
\hline Soil Type & $\begin{array}{l}\mathbf{R}^{2} \\
(-)\end{array}$ & $\begin{array}{l}\text { CV } \\
(\%)\end{array}$ & $\begin{array}{l}\text { Intercept } \\
\left(\mathrm{L}^{-1}\right)\end{array}$ & $\begin{array}{l}\text { tion Termsل } \\
\text { Density } \\
\left(\mathrm{L}^{2} \mathrm{M}^{-1}\right)\end{array}$ & $\begin{array}{l}\text { Water } \\
\left(L^{-1}\right)\end{array}$ & $\begin{array}{r}\text { Density2J } \\
\left(\mathrm{L}^{5} \mathrm{M}^{-2}\right)\end{array}$ & $\begin{array}{c}\text { Water } 2 / \\
\left(L^{-1}\right)\end{array}$ \\
\hline Lakeland & 0.97 & 1.2 & 0.251 & $\overline{-0.086}$ & 0.19 & $\overline{.0841}$ & $\overline{-0.29}$ \\
\hline Cecil I & 0.99 & 1.15 & $\overline{0.0111}$ & 0.23 & 0.20 & $\overline{-0.0175}$ & $\overline{-0.18}$ \\
\hline Cecil II & 0.99 & 1.5 & $\overline{0.029}$ & 0.21 & 0.17 & $\overline{-0.0075}$ & -0.10 \\
\hline Troup & 0.93 & 1.5 & 0.672 & $\overline{-0.5}$ & 0.2 & 0.185 & $\overline{-0.11}$ \\
\hline Wilcox & 0.67 & 2.5 & $\overline{1.228}$ & $\overline{-1.86}$ & 0.8 & $\overline{1.0001}$ & -0.2 \\
\hline
\end{tabular}

I An overscore denotes lack of significance at the $5 \%$ level. An evaluation with density $x$ water cross product showed this term to be insignificant $(P \leq 0.05)$ in all situations.

2f The units for water content and density for use in these equations are:

$$
\begin{aligned}
& \text { water content - dimensionless fraction } \\
& \text { density } \quad-\mathrm{Mg} / \mathrm{m}^{3}
\end{aligned}
$$

Regression analysis results by soil using a linear model with an intercept are summarized in Table 5. The intercept term from each equation was significant at the $1 \%$ level, which was not expected from Eq. (5). X-ray absorption coefficients predicted for water were generally close to the accepted known value of $0.191 \mathrm{~cm}^{-1}$. The observed soil density term was less than that which would be expected from Eq. (6). In most cases, the density term compares favorably with similar terms reported by Anderson et al. (1986). Uncertainties in the wavelength distribution, coupled with unknown filtering functions in the reconstruction algorithm, may explain the discrepancy. Further studies which correlate photodetector gain settings with absorption levels may lead to better estimates of the absorption coefficient of dense materials. 
Table 5. Regression Analysis of the Linear Model for the Five Test Soils

\begin{tabular}{lcccccc}
\hline Soil Type & $\begin{array}{c}\mathrm{R}^{2} \\
(-)\end{array}$ & $\begin{array}{c}\mathrm{CV} \\
(\%)\end{array}$ & $\begin{array}{c}\text { Intercept } \\
(\text { unit) }\end{array}$ & $\begin{array}{c}\text { Eensity }\left(\mu_{\mathrm{s}}\right) \\
(-)\end{array}$ & $\begin{array}{c}\text { Waier }\left(\mu_{\mathrm{w}}\right) \\
(-)\end{array}$ & $\mu_{\mathrm{s}} / \mu_{\mathrm{w}}$ \\
\hline Lakeland & 0.97 & 1.2 & $0.0789 \pm 0.007$ & $0.413 \pm 0.012$ & $0.186 \pm 0.01$ & 2.22 \\
Cecil I & 0.99 & 1.2 & $0.0439 \pm 0.003$ & $0.495 \pm 0.005$ & $0.171 \pm 0.01$ & 2.90 \\
Cecil II & 0.99 & 1.5 & $0.0440+0.013$ & $0.513 \pm 0.006$ & $0.150 \pm 0.01$ & 3.42 \\
Troup & 0.92 & 1.5 & $0.1488 \pm 0.013$ & $0.335 \pm 0.021$ & $0.180+0.01$ & 1.86 \\
$\begin{array}{l}\text { All Soils Except } \\
\text { Wilcox }\end{array}$ & 0.97 & 2.5 & $0.0514 \pm 0.004$ & $0.478 \pm 0.007$ & $0.191 \pm 0.01$ & 2.50 \\
\hline
\end{tabular}

עUnits of density and water are dimensionless. Density is expressed as density/2.65.

Water is expressed as a fraction.

Using various water bodies with and without surrounding soil, Tollner et al. (1989) found that soil surrounding a body of water did not significantly affect the predicted absorption coefficient for water. This suggests that the reconstruction algorithm successfully compensates for $\mathbf{x}$-ray spectrum shifts (which depend on object material and size) for absorbing material similar to the calibration references. It appeared that one cannot precisely predict absorption coefficients for other materials, but that one can estimate the direction of change of the coefficient relative to a known material. Results of a regression analysis without an intercept and with a fixed water coefficient of $0.191 \mathrm{~cm}^{-1}$ are shown in Table 6. The restriction of $0.191 \mathrm{~cm}^{-1}$ for water did not prove significant for any soil in Table $6(\mathrm{P} \leq 0.05)$. Using the constant for water and removing the intercept resulted in near identical values for the density term. Iron appeared to affect the soils term in Table 6 at the second decimal place. Further evaluations are needed which involve higher iron contents than those tested.

Considering Eq. (6), an effective mean wavelength shift from $0.19 \times 1010 \mathrm{~m}$ to $0.125 \times 1010$ $\mathrm{m}$ would result in a value for the ratio of soil absorption to water absorption $\left(\mu_{\mathrm{s}} / \mu_{\mathrm{w}}\right)$ of $3.44=$ [2.65(10.83/6.63)(0.143/0.213)], which is in the vicinity of values tabulated in Table 6. Actually, both the wavelength shift along with changes in gains would account for differences in predicted coefficients for solids (from Eq. (6)) vs. observed coefficients. Separating the gain effect from the wavelength shift affect appears to be a formidable problem.

Based on findings in this study, one could calibrate a soil under study by establishing various dry density levels, scanning, and then determining the coefficient for the test soil. Unless the mineralogy was unusual or the scanner was different, values near those obtained herein should result. $t$ le coefficient for water would not be expected to change. These results suggest that the water cuefficient is nearly invariant with soil, further suggesting it need not be determined for individual soils. 
Table 6. Regression Analysis Using the Linear Model. Intercepts and the Water Coefficient Forced to the Standard Measured Value of $0.191 \mathrm{~cm}^{-1}$

\begin{tabular}{llc}
\hline Soil Type & $\begin{array}{c}\mu_{\mathrm{S}} \\
(-)\end{array}$ & $\begin{array}{c}\mu_{\mathrm{S}} / 0.191 \\
(-)\end{array}$ \\
\hline Lakeland & 0.557 & 2.92 \\
Cecil I & 0.574 & 3.01 \\
Cecil II & 0.588 & 3.08 \\
Troup & 0.559 & 2.93 \\
All Soils Except Wilcox & 0.570 & 2.98 \\
\hline
\end{tabular}

The relationship in Table 6 could probably be applied to the Wilcox clay once a suitable correction for iron was determined. The predominant mineral in the Wilcox soil is montmorillinite, which has a similar effective atomic weight to most other soil minerals. X-ray CT may thus be applicable to studying the dynamics of soil swelling, particularly if an independent measure of either volumetric water or density was available.

\section{Conclusions}

The x-ray absorption, soil, and soil water calibration study lead to the following conclusions:

1. A linear relationship among the absorption coefficient for solids and liquid portions enables coefficients for each phase to be measured independently, greatly facilitating calibration.

2. The standard, measured absorption value for water of $0.191 \mathrm{~cm}^{-1}$ was duplicated, implying that one need not determine this coefficient for each soil.

3. Additional empirical relationships andior theory is needed for predicting the absorption coefficient for solids based on known values for water. It is felt that the theory would provide order of magnitude estimates of the solids' absorption coefficient relative to the water absorption coefficient. Further studies are ne ded to factor in the photomultipiler gain settings so as to better predict the absorption of solids relative to water. Separating the wavelength shift effect from the photomultiplier gain effect appears to be difficult.

4. For all soils tested, except the Wilcox clay, the predicted soil density term was constant within $5 \%$ when the water term was fixed.

\section{Asknowledgements}

The study was partially supported by a grant from Westinghouse Savannah River Company and by the funds from Georgia Agricultural Experiment Stations. The data collection efforts of Mr. Stan Thain are acknowlerlged. Appreciation is extended to Dr. L.M. Shuman for providing the iron analysis. Thanks to Ms. Doris Walton for clerical assistance. 


\section{References}

Anderson, S.H., C.J. Gantzler, J.M. Borne, and R.J. Tulley, "Rapid nondestructive bulk density and soil-water content determination by computed tomography," Soil Sci. Soc. Am. J. 52,35-40 (1988).

Anon. Performance evaluation of Somaton $R$ Version $H$, Siemens Medical Systems, Inc., Islin, NJ (1986).

Baver, L.D., W.H. Gardner, W.R. Gardner, Soil Physics, 4th Ed. (John Wiley and Sons, New York, NY 1972).

Cheshire, J.M. Jr., E.W. Tollner, B.P. Verma and W.M. Blum, "Radiographic detection of soil incorporated granular pesticides and impacts of application methods on wireworm management," TRANSACTIONS of the ASAE 32(2),415-423 (1989).

Crestano, S., S. Mascarenhas, and R.S. Pozzi Mucelli, "Static and dynamic 3-dimensional studies of water in soil using computed tomographic scanning," Soil Science 140,326-332 (1985).

Dixon, J.B. and S.B. Weed, Minerals in Soil Environments, Soil Science Society of America, Madison, WI (1977).

Garrett, R. and D.H. Lenker,"Selecting and sensing x- and gamma rays," Quality Detection of Foods, J.J. Gaffney "Ed.", ASAE Special Publication 1-76, pp. 106-109, 114. American Society of Agricultural Engineers, St. Joseph, MI (1984).

Hainsworth, J.M. and L.A.G. Aylemore,"Water extaction by single plant roots," Soil Sci. Soc. Am. J. 50,841-848 (1986).

Herman, G.T., Image reconstruction from projections: The fundamentals of computed tomography, ( Academic Press, New York, NY, 1980).

Klute, A. "Ed.", "Methods of soil analysis, Part I: Physical and mineralogical methods," 2nd ed. ASA No. 9 (Part 1). American Society of Agronomy, Madison, WI (1986).

McCullough, E.C., "Photon attenuation in computed tomography," Med, Phys. 2,307-320 (1975).

Petrovic, A.M., J.E. Siebert, and P.E. Rieke, "Soil bulk density analysis in 3-dimensions by computed tomographic scanning," Soil Sci. Soc. Am. J. 46,445-450 (1982).

Richards, J.A., F.W. Sears, M.R. Wehr, and M.W. Zemansky, Modern University Physics (Adison-Wesley, London, England, 1960).

SAS Institute, SAS User's Guide: Basics, SAS Institute, Inc., Cary, NC (1985).

Shuman, L.M., "Zinc, manganese and copper in soil functions," Soil Science 127,1-17 (1979).

Tollner, E.W., J.W. Davis, and B.P. Verma, "Managing errors with x-ray computed tomography (x-ray CT) when measuring physical properties," TRANSACTIONS of the ASAE 32(3),10901096 (1989). 
Tollner, E.W. and B.P. Verma, "X-ray CT for quantifying moisture at points within a body of soil," TRANSACTIONS of the ASAE 32(3),905 (1989).

Weast, R.C. "Ed.", Handbook of Chemistry and Physics, "50th ed." (Chemical Rubbert Company, Cleveland, $\mathrm{OH}, 1969$ ). 


\title{
II. INTERPRETING THE PIXEL STANDARD DEVIATIOON STATISTIC FROM AN X-RAY TOMOGRAPHIC SCANNER
}

\author{
E.W. Tollner, Ron Harrison, C. Murphy
}

\begin{abstract}
The pixel standard deviation, along with mean absorption, represent two quantitative outputs from $\mathrm{x}$-ray computed tomography ( $\mathrm{x}$-ray $\mathrm{CT}$ ). The standard deviation is a measure of dispersion of individual pixel absorption values. An approach for using the standard deviation statistic in interpreting image "texture" was developed and is investigated using specially constructed fixtures. The theory assumes the region could be subdivided into two or three regions having known absorption values and having a known background standard deviation. Using the model, predicted vs. observed, standard deviation agreed within $20 \%$ for the worst case. Prediction of pixel numbers representing pore media agreed with actual pixels within $20 \%$ for the most promising case. The standard deviation statistic appears to be a significant aid in image interpretation.
\end{abstract}

\section{Introduction}

$\mathrm{X}$-ray computed tomography (x-ray CT) has been shown to be useful for imaging interior regions of soil bodies. The mean absorption has been related to the density of soil solids and to soil water content (Tollner and Murphy, 1990). Another statistic which is frequently computed is that of pixel standard deviation. Pixel standard deviation $\left(S_{p}\right)$ is a measure of dispersion in the population of mean absorption values arising from the individual pixels comprising the region of interest.

Pixel standard deviation $\left(S_{p}\right)$ is potentially interesting in that it may form the basis of an independent relationship such as

$$
S_{p}=f \text { (constituent 1, consituent(s) } 2 \text {....) }
$$

where constituent 1 may represent a "background" soil body and constituent(s) 2 may represent diverse entities such as macropores, soil insects, soil larvae, etc. Tollner et al. (1990) have explored a similar relationship for the mean $\mathrm{x}$-ray absorption. Judicious use of two relationships relating mean absorption as well as pixel standard deviation could enlarge the scope of measurable unknowns with the tomographic scanner. The pixel standard deviation may also be useful in image interpretation in instances where there are two or three constituents and one knows or can estimate absorption coefficients of the constituents.

\section{Objectives}

The objectives of this study were to:

1. Develop a rationale for interpreting the pixel standard deviation statistic.

2. Investigate the rationale using simplified objects.

Respectively, Associate Professor, Department of Agricultural Engineering, The University of Georgia, Georgia Experiment Station, Griffin, GA 30223-1797; Graduate Student, Entomology Department, The University of Georgia, Georgia Experiment Station, Griffin, GA 30223-1797; and Ecologist, Westinghouse Savannah River Corporation, Aiken, South Carolina. 


\section{Model Derivation}

The pixel standard deviation is defined as

$$
S_{p}=\left[S\left(X_{i}-\bar{X}\right)^{2 /(N-1)}\right] 1 / 2
$$

where

$$
\begin{aligned}
& S_{p}=\text { standard deviation }(\mathrm{cm}-1), \\
& N=\text { number of pixels in the region, } \\
& X=\text { mean x-ray absorption (cm-'), } \\
& X_{i}=x-\text { ray absorption for the } i \text { th pixel. }
\end{aligned}
$$

The pixel deviation squared is the sum of actual variance $\left(S_{\mathrm{a}}^{2}\right)$ plus the noise variance $\left(\mathrm{S}_{\mathrm{n}}{ }^{2}\right)$ as stated in Tollner et al. (1989). Eq. (1) can be exparded as follows when discreet regions of
known absorption comprise the region:

$$
S_{p}-S_{a}=\frac{1}{n-1} \sum_{L=1}^{L_{T}}\left(X_{L}-\bar{X}\right)^{2}+\frac{1}{n-1} \sum_{M=1}^{M_{T}}\left(X_{M}-\bar{X}\right)^{2}
$$

when

$$
\mathrm{L}_{\mathrm{T}}, \mathrm{M}_{\mathrm{T}}=\text { number of pixels representing these subregions respectively, }
$$

$$
\mathrm{X}_{\mathrm{L}}, \mathrm{X}_{\mathrm{M}}=\text { mean absorption of these respective subregions. }
$$

$$
\text { Also, } \quad \mathrm{L}_{\mathrm{T}}+\mathrm{M}_{\mathrm{T}}=\mathrm{N}
$$

Eq. (2) assumes that two regions of consistent absorption levels comprise the test region. It is assumed the background noise $\left(S_{n}\right)$ is the same over the entire image and also presumes true independence and accuracy in the pixel data regardless of surroundings. Tollner et al. (1989) found that autocorrelations had to be lagged by four pixels before becoming independent; thus, true independence is somewhat questionable. An expression for the mean absorption as a function of two regions of known absorption can be written as

$$
\mathbf{X}_{0}=\frac{\mathbf{L}_{T} \mathbf{X}_{\mathrm{L}}}{\mathrm{N}}+\frac{\mathbf{M}_{\mathrm{T}} \mathbf{X}_{\mathrm{M}}}{\mathrm{N}}
$$

where the symbolism is as defined above.

The key assumption of Eq. (3) is that one can precisely determine the mean of the pore media regardless of background surroundings. Equations (2), (2a), and (3) represent three equations available for the solution of up to three unknown variables. The respective absorption of the subregion is presumed known or, measurable apriori. The total size and individual pixel size is presumed known and the size of each subregion is presumed unknown. The scope of the present effort was limited to studying the factors affecting the application of equations (2), (2a), and (3) with tomographic scanning.

\section{Materials and Methods}

The effect of pore size on pixel standard deviation statistics was evaluated using wood and plexiglass blocks as background media. Pore, as used in this report, refers to the air or water media occupying the subregions of the wood or plexiglass background media. Blocks with dimensions of $222.5 \mathrm{~mm}^{2} \times 38.1 \mathrm{~mm}$ wide were used. The wood block was cut from pressure treated southern pine and coated six times with Sanding Sealer. Three $12.7 \mathrm{~mm}$ sheets of acrylic 
were glued with silicon to form the plexiglass block. The blocks were supported in a wooden box (outside coordinates of $305 \mathrm{~mm} \times 90 \mathrm{~mm} \times 260 \mathrm{~mm}$, inside coordinates of $275 \times \mathrm{mm} 55 \mathrm{~mm} \times$ $245 \mathrm{~mm}$ ) and first scanned to determine histograms.

Blocks were scanned using an EMI 5005 scanner at $120 \mathrm{KV}, 691 \mathrm{~mA}$.s. Collimation width was $13 \mathrm{~mm}$ and a pixel matrix of $320 \times 320$ was used with each pixel representing $1.07 \mathrm{~mm} \times$ $1.07 \mathrm{~mm}$. Sixteen holes (pores) were drilled completely through the material in a $152.4 \mathrm{~mm} \times$ $152.4 \mathrm{~mm}$ grid by means of a $3.2 \mathrm{~mm}$ bit. 'Pores were spaced $38.1 \mathrm{~mm}$ apart.

Each block was scanned in air and then immersed in a nine-liter, water-filled bag in the blockholding device (Figure 1).

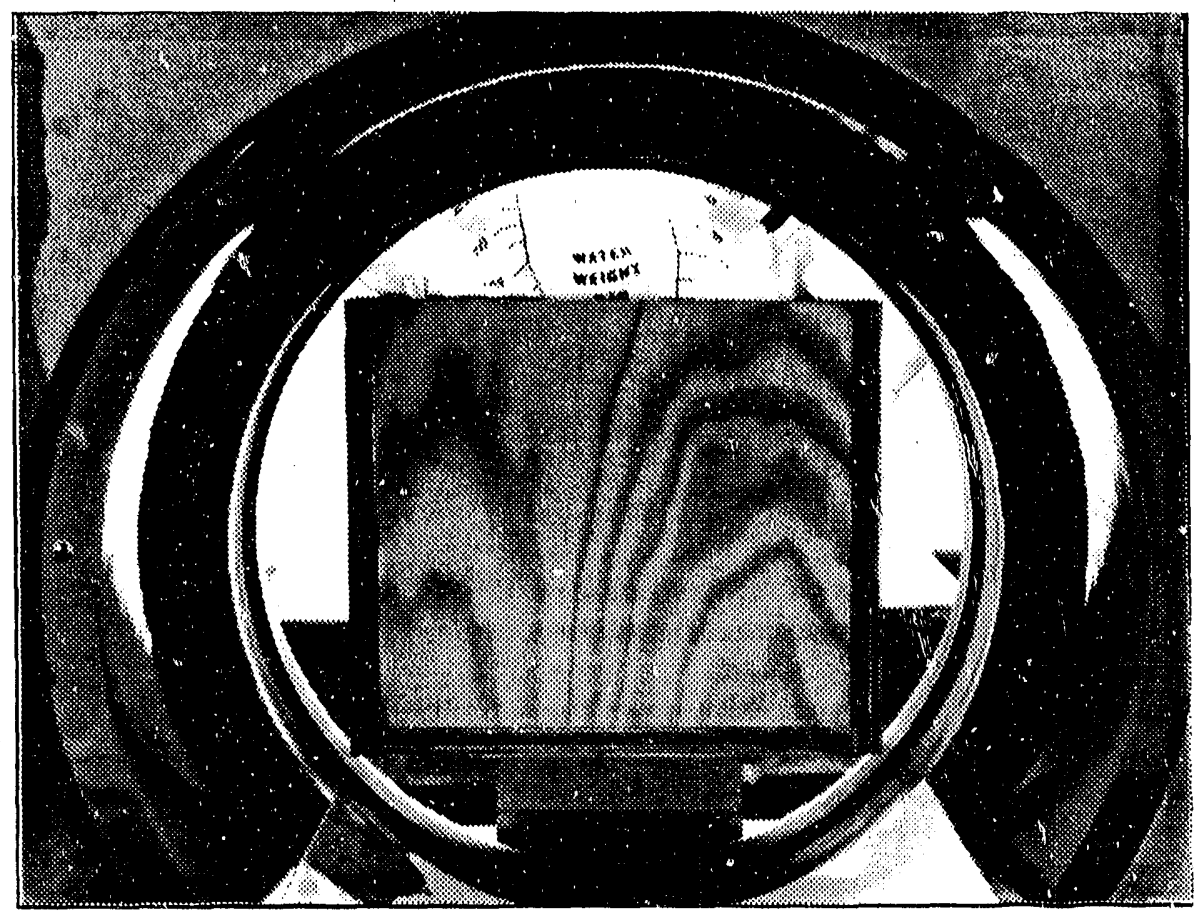

Figure 1. Photograph of Fixture for Supporting the Water-Submerged Wood and Plexiglass Media in the Scanner Gantry.

The drilled blocks were inserted individually into the bag and care taken to insure all pores were water saturated. Following completion of the first scan series (i.e., plexiglass dry, wood dry, plexiglass wet, wood wet), the pore size was increased by $3.2 \mathrm{~mm}$ and then scanned again. Pore sizes of 3.2, 6.4, 9.6, 12.8 and $16.0 \mathrm{~mm}$ were evaluated. A summary of background and pore media are included in Table 1. Multiple scans were made of each background media conditions to verify that the mean and standard deviation absorbance varied by less than one percent. For this report, air has an absorption of $0.0 \mathrm{~m}^{-1}$, while water has an absorption of $0.0191 \mathrm{~m}^{-1}$. 
Table 1. Selected Results From the Controlled Media Experiment

\begin{tabular}{|c|c|c|c|c|c|c|c|c|c|}
\hline $\begin{array}{l}\text { Background } \\
\text { Media } \\
\text { (1) }\end{array}$ & $\begin{array}{c}\text { Pore } \\
\text { Media } \\
(2) \\
\end{array}$ & $\begin{array}{c}\text { Pore } \\
\text { Size } \\
(\mathrm{mm}) \\
(3)\end{array}$ & $\begin{array}{l}\text { Actual } \\
\text { Pixels } \\
(4)\end{array}$ & $\begin{array}{c}\text { Calculated } \\
\text { pore } \\
\text { Absorption2/ } \\
\left(\mathrm{cm}^{-1}\right) \\
(5) \\
\end{array}$ & $\begin{array}{l}\text { Calculated } \\
\text { Hole } \\
\text { Sid. Dev.2/ } \\
\left(\mathrm{cm}^{-1}\right) \\
(6) \\
\end{array}$ & $\begin{array}{c}\text { Pixel } \\
\text { Ratio3/ } \\
(\%) \\
(7) \\
\end{array}$ & $\begin{array}{c}\text { Overall } \\
\text { Mean4/ } \\
\left(\mathrm{cm}^{-1}\right) \\
(8) \\
\end{array}$ & $\begin{array}{c}\text { Overall } \\
\text { Measured } \\
\text { Std. Dev. } 4^{\prime} \\
\left(\mathrm{cm}^{-1}\right) \\
(9) \\
\end{array}$ & $\begin{array}{c}\text { Overall } \\
\text { Calculated } \\
\text { Std. Dev. } \\
\left(\mathrm{cm}^{-1}\right) \\
(10) \\
\end{array}$ \\
\hline Plexiglass & No pore & 0.00 & 0 & 0.213 & 0.004 & 0.000 & 0.213 & 0.005 & 0.005 \\
\hline Plexiglass & Air & 3.17 & 118 & 0.026 & 0.025 & 57.627 & 0.212 & 0.011 & 0.012 \\
\hline Plexiglass & Air & 6.35 & 474 & -0.001 & 0.006 & 54.852 & 0.210 & 0.020 & 0.025 \\
\hline Plexiglass & Air & 9.53 & 1066 & 0.001 & 0.006 & 72.514 & 0.205 & 0.033 & 0.038 \\
\hline Plexiglass & Air & 12.70 & 1894 & 0.002 & 0.005 & 82.471 & 0.199 & 0.047 & 0.050 \\
\hline Plexiglass & Air & 15.88 & 2960 & 0.002 & 0.005 & 88.412 & 0.191 & 0.059 & 0.062 \\
\hline Plexiglass & Water & 3.17 & 118 & 0.192 & 0.003 & 100.847 & 0.214 & 0.005 & 0.006 \\
\hline Plexiglass & Water & 6.35 & 474 & 0.191 & 0.004 & 86.076 & 0.215 & 0.006 & 0.005 \\
\hline Plexiglass & Water & 9.53 & 1066 & 0.191 & 0.004 & 85.272 & 0.214 & 0.006 & 0.007 \\
\hline Plexiglass & Water & 12.70 & 1894 & 0.191 & 0.004 & 98.680 & 0.213 & 0.007 & 0.007 \\
\hline Plcxiglass & Water & 15.88 & 2960 & 0.190 & 0.004 & 107.027 & 0.212 & 0.008 & 0.008 \\
\hline Woct & No pore & 0.00 & 0 & 0.076 & 0.098 & 0.000 & 0.098 & 0.015 & 0.015 \\
\hline Wood & Air & 3.17 & 118 & 0.037 & 0.019 & 98.305 & 0.098 & 0.016 & 0.016 \\
\hline Wood & Air & 6.35 & 474 & 0.039 & 0.016 & 84.177 & 0.097 & 0.019 & 0.012 \\
\hline Wood & Air & 9.53 & 1066 & 0.039 & 0.015 & 96.998 & 0.099 & 0.024 & 0.017 \\
\hline Wood & Air & 12.70 & 1894 & 0.043 & 0.014 & 94.984 & 0.098 & 0.028 & 0.020 \\
\hline Wood & Air & 15.88 & 2960 & 0.046 & 0.015 & 83.209 & 0.097 & 0.031 & 0.022 \\
\hline Wood & Water & 3.17 & 118 & 0.187 & 0.008 & 115.254 & 0.101 & 0.017 & 0.015 \\
\hline Wood & Water & 6.35 & 474 & 0.184 & 0.009 & 150.422 & 0.102 & 0.021 & 0.020 \\
\hline Wood & Water & 9.53 & 1066 & 0.186 & 0.006 & 122.983 & 0.104 & 0.024 & 0.025 \\
\hline Wood & Water & 12.70 & 1894 & 0.186 & 0.006 & 116.103 & 0.108 & 0.028 & 0.028 \\
\hline Wood & Water & 15.88 & 3454 & 0.188 & 0.006 & 116.689 & 0.112 & 0.033 & 0.031 \\
\hline
\end{tabular}

$1 /$ Calculated using the pixel size of $1.07 \mathrm{~mm} \times 1.07 \mathrm{~mm}$.

2/ Statistics calculated from the portion of the pixel histogram representing the pore, for pore size of zero; tabulated values represent the solid background.

3/ Pixel numbers recovered from histogram divided actual pixel, expressed as a percent.

4/ Statistics represent outputs for entire histogram.

5/ Calculated using Equation 2 based on actual numbers with the plexiglass or wood background noise (no pore) and predetermined absorbance values of $0.191 \mathrm{~cm}^{-1}$ for water pores and $0.00 \mathrm{~cm}^{-1}$ for air pores. 
From the viewing console, absorption values for each pore were determined with all pore sizes in both the plexiglass and the wood background under both air and water conditions. Pixel absorption histograms were also printed. Consistency among pixel absorption values within each scan were investigated using Univariate statistical procedures (SAS, 1985) and the Shapiro and Wilk ( 1965) normality test. From the pixel histogram, mean pore absorption and statistics were determined. The number of pixels represented by the pore media were recovered from the histogram. Using Eq. (2), predicted standard deviation for each scan was calculated and compared with observed values. Using equations (2), (2a) and (3), predicted numbers of pixels occupied by the pore media were calculated and compared with actual pixel numbers.

\section{Results and Discussion}

A typical scan involving plexiglass and water is shown in Figure 2. Constancy among pixel absorption values representing the pore media was investigated by determining minimum absorption values represented by each pore, or in the case of wood-water, the maximum absorption in each pore. Results for each pore were analyzed from the viewing console. All scans were analyzed in this manner.

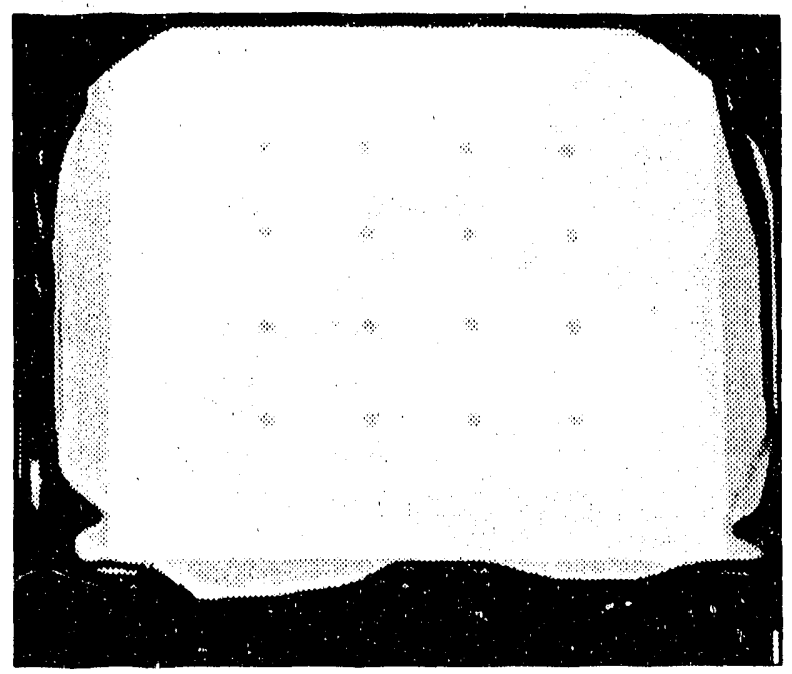

Figure 2. Photograph of X-Ray CT Image of Plexiglass in Water Showing Pores Background Contrast.

Wood was more absorbing of $\mathrm{x}$-rays than air, but less absorbing than water. For all but the smallest pore size in wood-air, absorption values approached $0.003 \mathrm{~m}^{-1}$, suggesting an influence on the predicted value by the surrounding wood. This was also observed in Tollner et al (1989). With water in the pores, the means for all pores approached expected values for water and the values were normally distributed $(P<0.01)$ using the Shapiro and Wilk (1965) test.

With plexiglass, both pore niedia were less dense. For each of the sixteen pores, minimum xray absorption levels represented by pore media were determined. These levels closely approximated expected absorption levels for air and water, respectively, and were normally distributed $(P<0.01)$ for the smallest $(3.2 \mathrm{~mm}$ diameter) pores. The absorption means at the smallest pore size were substantially larger, especially with air, suggesting a lack of independence in the individual pixel data for small regions. 
The pixel histogram for each scan was analyzed by (l) determining the region of the histogram representing the pore; (2) calculating the mean absorption and standard deviation for the pore media; and (3) determining the total pixels representing pore media. An example of a pixel histograin representing plexiglass-air (15.88 $\mathrm{mm}$ diameter) is shown in Figure 3, with the large peak representing the plexiglass and the small peak representing pore air.

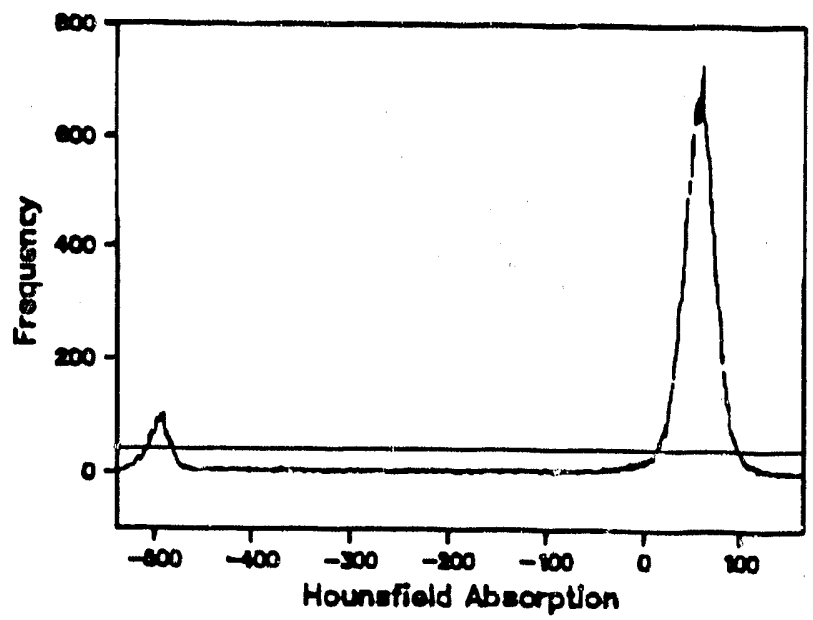

Figure 3. Plot of Pixel Histogram from Plexiglass-Air Study.

The pore mean was tabulated in Column 5, Table 1. In the plexiglass, the calculated value for the absorption coefficient of air npproached $0.0 \mathrm{~m}^{-1}$ except for the smallest pore. The smallest pore exceeded the four-pixel diameter which was found by Tollner et al. (1989) to be the limiting length where independence existed. Thus, with the smallest pore filled with air, the surrounding plexiglass affected the value for the pore. Calculated values for water closely approximated the expected value of $0.0191 \mathrm{~m}^{-1}$. The effect of pore size was not nearly as great when the pore media was water.

With wood, the computed absorption mean for air was notably higher than in the plexiglass. The calculated absorption mean for water was somewhat lower than the expected value of 0.0191 $\mathrm{m}^{-1}$. These discrepancies may have been due to difficulties in adequately separating the pore media from the background on the pixel histograms involving the wood media. Absorption properties of wood-water and wood-air are relatively close and the standard deviation inherent with the wood media was much larger than in the case of the plexiglass (compare plexiglass-no pore and wood-no pore, Column 6 of Table 1).

Calculated standard deviation for pores are shown in Column 6 of Table 1. Except for the smallest pore size (plexiglass-air), values for plexiglass closely approximated $0.0004 \mathrm{~m}-1$, which is the instrument noise level found in Tollner et al. (1989) under similar conditions. Calculated standard deviation values for air and water media in wood background were ligher. It appeared that the higher standard deviation associated with wood resulted from "F-ieeding" into the pore media, because values for both air and water were higher than the levels observed with plexiglass. The pore media mean and standard deviation results corroborated the findings based on the individual pore analysis, suggesting that valid estimates of pore media absorption can be determined rapidly from the viewing console.

A comparison of recovered pixels vs. actual pixels, expressed as a percent, is tabulated in Column 7 of Table 1 . In plexiglass, the recovery ranged from about $60 \%$ to near $100 \%$ with values approaching $100 \%$ as pore size increased. With wood-air, recovery ranged from $80 \%$ to near $100 \%$. This was attributed to some infiltration of water into the surrounding wood. 
Standard deviation values were calculated using Eq. (2), where $X$ was the measured overall mean (Table 1, Column 8), $\mathrm{X}_{\mathrm{L}}$ and $\mathrm{X}_{\mathrm{M}}$ were the background mean absorption and pore mean absorption, and $\mathrm{L}_{\mathrm{T}}$ and $\mathrm{M}_{\mathrm{T}}$ were the background pixels and pore pixels. Background absorption values were those measured with no pores present. Pore absorption values were the standard values for air and water, respectively. Background pixel numbers were calculated by subtracting the actual pixel number (Table 1, Column 4) from ${ }^{\prime}$ the total pixel number in the preset test region $(31,784)$.

Calculated (from Eq. (2); Table 1, Column 10) vs. measured (CT consol, Table 1, Column 9) standard deviation values for all test conditions are plotted in Figure 4. The maximum difference between calculated and measured standard deviation is $0.0003 \mathrm{~m}^{-1}$ for all cases except wood-air, where the maximum cieviation was $0.0009 \mathrm{~m}^{-1}$. The wood-air discrepancy was not surprising given the observed discrepancy for the mean absorption for air when surrounded by wood as opposed to plexiglass. Especially with plexiglass, discrepancies in observed vs. actual pixel number did not seem to have an overly adverse effect on predicted standard deviation.

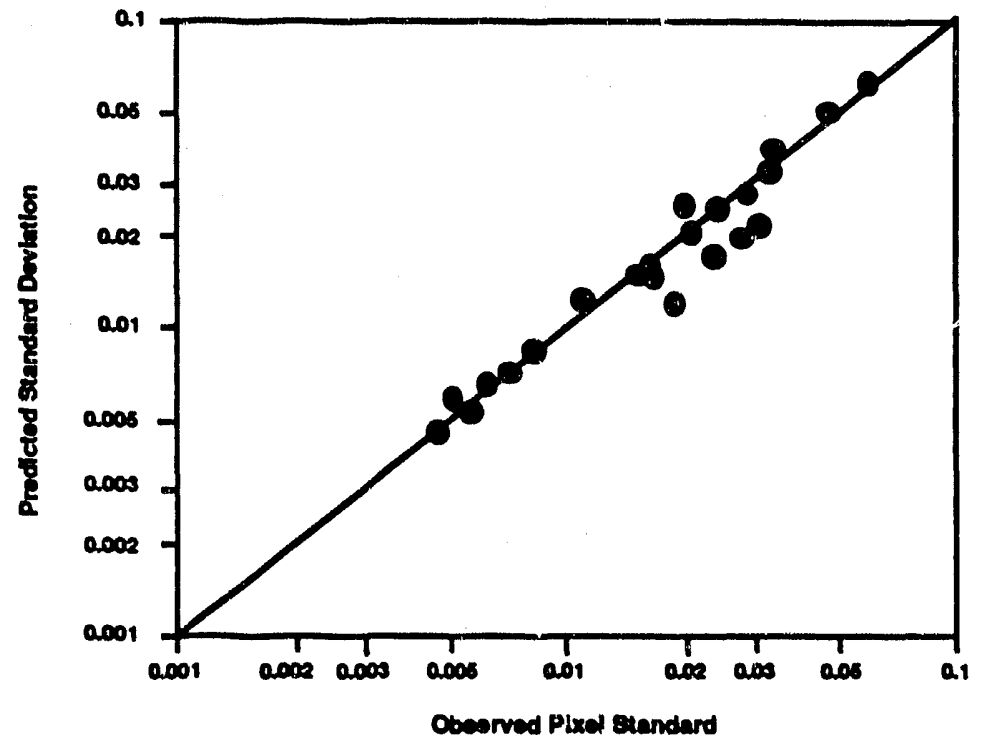

Figure 4. Calculated (from Eq. (2)) vs. Observed (CT Scanner) Pixel Standard Deviation Values.

Some similar calculations of the overall mean using Eq. (3), with inputs as defined above as needed, indicated much greater discrepancies in the computed mean vs. measured mean. This indicated that Eq. (3) was greatly affected by small departures in pixel numbers and in mean absorption values. The standard deviation (from Eq. (2)) is less affected by disurepancies in actual vs. assumed known mean values, as well as by actual vs. assumed known pixel numbers. The assumption of equal standard deviation value in the background and pore media was more or less met in the wood and plexiglass.

Using each combination of equations (2), (2a), and (3), predicted pixel numbers under each condition were computed. Values of $S_{n}$ were chosen based on the respective wood or plexiglass scan with no pores. Known absorption values for pore media (air, water) and background media (plexiglass, wood) were used with relevant overall means and standard deviation $\left(S_{p}\right)$ values and were brought in to represent each test case. Values $\mathbf{L}_{\mathrm{T}}$ and $\mathrm{M}_{\mathrm{T}}$ were then solved using equation processing software (UTS, 1987). Kesults uased on equations (2) and (2a), (3) and (2a), and (2) and (3). are shown in Figures 5a, 5b and 5c, respectively. 


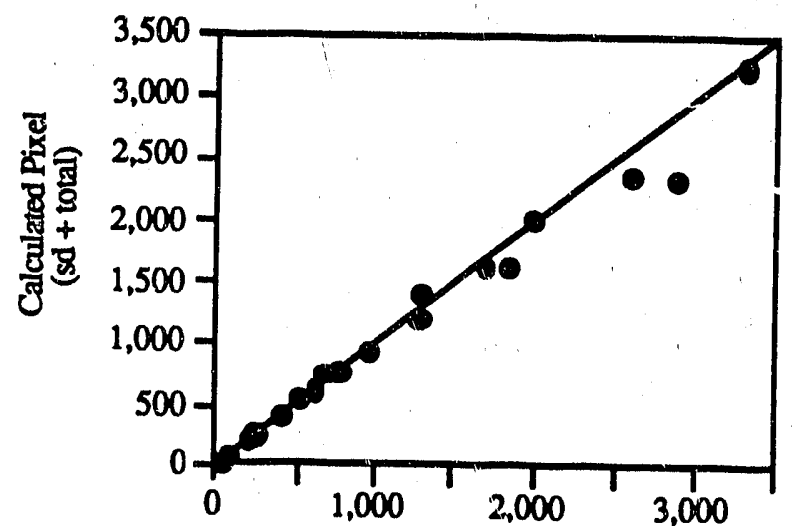

5a. Calculated (from Eq. (2,2a)) vs. Actual Pixel Numbers with Plexiglass and Wood Background with Air and Water Pore Space.

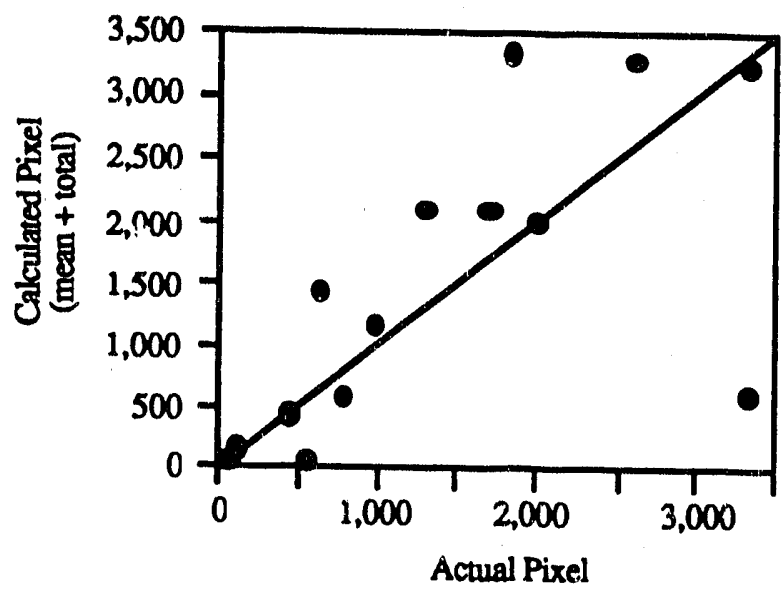

5c. Calculated (from Eq. $(2,3)$ ) vs. Actual Pixel Numbers with Plexiglass and Wood Background with Air and Water Pore Space.

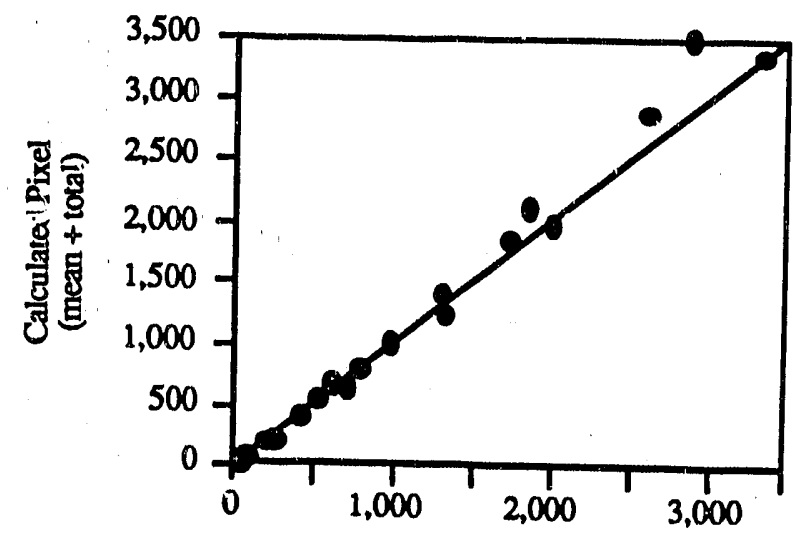

5b. Calulated (from Eq. (2a,3)) vs. Actual Pixel Numbers with Plexiglass and Wood Background with Air and Water Pore Space.

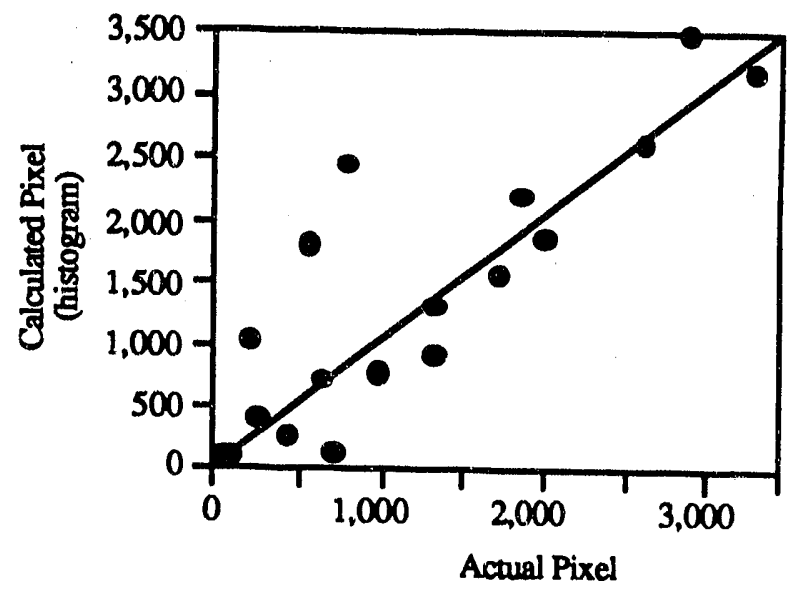

51. Predicted (Histograrn) vs. Actual Pixel Numbers with Plexiglass and Wood Background with Air and Water Pore Space.

Those combinations involving Eq. (2) (Figures $5 \mathrm{a}$ and $5 \mathrm{c}$ ) resulted in much better approximation than did Eq. (3) with Eq. (2a) (Figure 5b). Prediction of pixel numbers based on known total pixels and known background and pore med:a absorption values (Equation 3, 2a Figure 5b) was not considered successful because these equations were greatly affected by discrepancies in assumed versus measured mean values for the pore material. This was especially true in the case of plexiglass-water. Those cases involving Eq. (2) (Figures 5a, 5c) were reliable to within $20 \%$ and considered successful. The total pixels predicted by Eq. (2a) and Eq. (3) added to the known value within $20 \%$. Figure $5 \mathrm{~d}$ is a plot of predicted (from the histogram) vs. actual pixels. The data are also tabulated in ratio form in Column 7 of Table 1.

The results suggest that, given a media which can be characterized by two levels of x-ray absorption and one background standard deviation $\left(S_{n}\right)$, one can use mean standard deviation outputs to solve for pixel numbers falling within each category. In all, three equations were identified suggesting the theoretical possibility of quantifying three regions in cases where it would be desirable. 
In some preliminary tests, the technique was applied to the characterization of pecan larvae burrowing activity in prepared soils. Background absorption and standard deviation $\left(\mathrm{S}_{n}\right)$ was determined on cores before larval introduction. Detailed measurements were made on several zones obviously affected by larval activity, based on analyses from the viewing console (or from pixel histograms). Solution of Eq. (2) and Eq. (3) resulted in reasonable numbers, typical of background and soil affected by the larvas.

From a more general point of view, the pixel standard deviation statistic enables the accomplishment of one major objective in image analysis, that of defining pixel numbers falling into one of two categories. The number of categories could possibly be generalized to three. The advantage of the approach is that expensive image analysis software and hardware attachments are not required in order to obtain pixel number data. However, the standard deviation approach does not appear to enable more detailed image characterization such as that discussed by McBratney and Moran (1990), who were interested not only in pixel number but more detailed feature analysis.

\section{Conclusions}

A model for predicting the overall pixel standard deviation was developed by assuming the histogram to be comprised of two (or three) distributions having the same underlying standard deviation $\left(S_{n}\right)$. This assumption proved to hold reasonably well. Specific conclusions drawn were:

1. Pore media (air, water) absorption standard deviations were accurately predicted except when pore size was small or when the background media more closely approximated the pore media in terms of $\mathrm{x}$-ray absorption.

2. Pixels representing pores were predicted to within $20 \%$ using the standard deviation equation (2), coupled with the equation (2a) for total pixels or the mean absorption equation (3).

3. The technique can be used for rudimentary image analysis when two or possibly three distributions comprise the pixel histogram.

\section{Acknowledgements}

The authors express appreciation to Westinghouse $S$ vannah River Company for funding the research. Thanks also to Mr. Stan Thain for data collection and analysis efforts. Appreciation is expressed to Ms. Doris Walton for clerical assistance 


\section{References}

McBratney, A.B. and C.J. Moran, "A rapid method of analysis for soil macropore structure:

Stereological model, statistical analyses and interpretation," Soil Soc. Am. J. 54,509-515 (1990).

SAS Institute, SAS User's Guide - 5th Edition. SAS Institute, Inc., Cary, NC (1985).

Shapiro, S.S. and M.B. Wilk, "An analysis of variance test for normality (complete samples)," Biometrika 52,591-611 (1965).

Tollner, E.W. and C. Murphy, "Factors affecting the absorption of X-rays by soil with computed tomography," In preparation for TRANSACTIONS of the ASAE (1990).

Tollner, E.W., J.W. Davis and B.P. Verma, "Managing erro.s with X-ray computed tomography (x-ray CT) when measuring physical properties," TRANSACTIONS of the ASAE 32(3),10901096 (1989).

UTS, TK Plus Solver, Universal Technical Systems, Rockford, IL (1987). 


\title{
III. TECHNIQUES AND APPROACHES FOR DOCUMENTING PLANT ROOT DEVELOPMENT WITY X-RAY COMPUTED TOMOGRAPHY
}

\author{
E.W. Tollner, C. Marphy, E.L. Ramseur
}

\begin{abstract}
Quantification of pot activity in terms of root growth and indirectly through water uptake is necessary for understanding plant growth dynamics. X-ray computed tomography (CT) enables qualitative as well as two quantitative outputs, one of which can lead to conclusions regarding root activity. A greenhouse study involving soil columns (Lakeland sand, bulk density $1.4 \mathrm{Mg} / \mathrm{m}^{3}$ ) rlanted to soybean, Bahiagrass, and a control (no vegetation) was conducted in 1989. A treflan based chemical barrier was placed in half of the soil column of each species. The mean x-ray absorption correlated to water content. Results suggested that root presence can also be indirectly inferred based on water content drawn down during planned stress events. It was concluded that $x$-ray CT may have a niche in soil-water-plant relation studies, particularly when plant species have large roots.
\end{abstract}

\section{Introduction}

Understanding soil moisture and plant ronting dynamics over time on a smail scale can yield significant insight in $c$ many soil-water-plant relations of practical interest. Effects of old rooting channels, earthworm channels, and soil cracks cannot be easily studied without nondestructive sensing capability. X-ray computed tomography (CT) computes x-ray absorption coefficients on a nearly continuous basis within solid objects such as soils. X-ray CT does not appear to be adversely affected by soil iron. Magnetic resonance imaging (MRI) does suffer from the iron limitations (Rogers and Bottomley, 1989).

That $\mathrm{x}$-ray CT can produce visual qualitative images of agricultural systems is now fairly well known. This subject was recently reviewed by Tollner et al. (1987). Work towards using $\mathrm{x}$-ray CT for quantitative purposes is just beginning. Anderson and Gantzler (1987) showed a relationship between volumetric moisture content and mean $\mathrm{x}$-ray attenuation for several soils. Tollner et al. (1989) studied water distribution in sands using x-ray CT. Tollner and Murphy (1990a) have shown that mineralogy is the factor having the major bearing on the relationship. Soils with high iron or illite fractions appeared to be the only soils requiring special calibration. Brown et al. (1987) used x-ray CT for stı dying water distribution in several porous foams. Using foam material of consistent dry density, iney correlated $x$-ray CT Hounsfield units with gravimetric water content in the foam. Hainsworth and Aylmore (1986) constructed a CT scanner with a 100 mm diameter capability, which has proven useful in studying soil-water uptake by roots.

Respectively, Associate Professor, Department of Agricultural Engineering, University of Georgia, Georgia Experiment Station, Griffin, GA 30223-1797; Ecologist, Westinghouse Savannah River Company, Aiken, South Carolina 29808; Assistant Professor, Department of Agronomy, University of Georgia, Georgia Experiment Station, Griffin, GA 30223-1797. 
$\mathrm{X}$-ray CT Hounsfield units, the customary units of $\mathrm{x}$-ray CT, are related to $\mathrm{x}$-ray attenuation (units of $\mathrm{cm}^{-1}$ ) equation:

$$
\mathrm{H}(\mathrm{x} y)=\left\{\left[\mu(\mathrm{x}, \mathrm{y})-\mu_{\mathrm{w}}(1000)\right] / \mu_{\mathrm{w}}\right\} \times 0.191
$$

where

$$
\begin{aligned}
& \mathrm{H}(\mathrm{x}, \mathrm{y})=\text { computed Hounsfield units as a function of position, } \\
& \mu(\mathrm{x}, \mathrm{y})=\mathrm{x} \text {-ray attenuation coefficient as function of position }\left(\mathrm{L}^{-1}\right), \\
& \mu_{\mathrm{w}} \quad=\mathrm{x} \text {-ray attenuation coefficient of water }\left(L^{-1}\right) .
\end{aligned}
$$

$\mathrm{X}$-ray tomographic scanners provide mean absorption and pixel standard deviation for specified regions. Pixel absorption distribution (histograms) can also be printed. The pixel standard deviation is discussed in detail by Tollner et at. (1990b). In a study of soil-root systems, the soil plus water would usually contribute to most of the total absorption. With constant density and water content over time, pixel histograms for regions with developing roots should show an increasing number of outlying points on the minimum side as time progresses, assuming that roots or voids in the image caused the lowest absorption values. Tollner et al. (1989) presented data showing that values of individual pixels are repeatable to $\pm 5 \%$, suggesting that meaningful information can be gleaned from the outlier region of the pixel histogram. Variation in moisture content would cause shifts in the location on the absorption continuum, but the outlier zone should still be apparent.

\section{Objective}

The objective of this study was to relate x-ray CT outputs (mean absorption and pixel standard deviation) to plant root activity in soil systems with and without a treflan pellet barrier (biobarrier).

\section{Materials and Methods}

The plant rooting investigation was conducted using polyvinyl chloride (PVC) tubes with a diameter of $152 \mathrm{~mm}$ and approximately one meter in length. Tubes to be planted to soybean (Glycine Mar. Thomas VII) were cut into two $460 \mathrm{~mm}$ sections and tubes to be planted to Bahiagrass (Paspalum notatum) were cut into one $229 \mathrm{~mm}$ section and one $686 \mathrm{~mm}$ section. Control tubes were constructed to both the soybean and Bahiagrass specifications. Lakeland sand, which had been air dried and passed through a $2 \mathrm{~mm}$ screen. was placed in the tubes at a bulk density of $1.39 \mathrm{Mg} / \mathrm{Kg}( \pm 1 \%)$. All tubes were equipped to ailow bottom trainage. A pelletized treflan rooting barrier was placed between the sections of half the tubes. Individual hemispherical pellets mounted on a loosely woven fabric had a $5 \mathrm{~mm}$ radius and were spaced $38 \mathrm{~mm}$ apart on a square grid. The rooting barrier was placed as the columns were filled with soil. There were 16 tubes in all: three soybean with biobarrier, three soybean without biobarrier, three Bahiagrass with biobarrier, three Bahiagrass without biobarrier, three controls without biobarrier; one control with biobarrier as in soybeans; and one control with biobarrier as in Bahiagrass. Scanning depth and barrier placement is summarized in Table 1 for each treatment. 
Table 1. Scanning Locations and Root Barrier Placement

\begin{tabular}{llr}
\hline Variable & & Depth(mm) \\
& Soybean 1 & Bahiagrass \\
\hline D1 & 75 & 75 \\
D2 & 382 & 154 \\
Barrier2J & 457 & 229 \\
D3 & 532 & 304 \\
D4 & 830 & 830 \\
\hline
\end{tabular}

$1 /$ Blank tubes were constructed similar to soybean and Bahiagrass tubes

$2 /$ Barrier placed between tube section. Tubes not having the barrier were identical in every other respect.

Tubes were scanned immediately after packing using a EMI 5005 CT scanner (120 KVA, 693 Ma.S). Scans were made $75 \mathrm{~mm}$ below the surface, $75 \mathrm{~mm}$ above and below the rooting barrier, and $80 \mathrm{~mm}$ above the bottom of each tube. Images were constructed using a $320 \times 320$ pixel (1.14 $\mathrm{mm}, 2$ per pixel) resoiution. Images were archived to magnetic tape for subsequent analysis.

Following the initial scan, tubes were wetted to field capacity using a 50\% Hoaglands solution and planted (July 1, 1989). Tubes were maintained in a ventilated greenhouse except when scanned. Tubes were scanned as above approximately once per week. Water status of each tube was maintained by adding $1000 \mathrm{cc}$ Hoaglands solution (50\% strength) or de-ionized water on alternate days for the first 30 days. After 30 days, Hoaglands solution was used for all irrigations. Inflow rate measurements were made at Day 35 and Day 65 by observing the rate of intake of the water. Water stress was induced 40 days and 60 days into the study by planned interruptions of the watering schedule. At other times, all tubes showed evidence of bottom drainage. After scannirg on Day 84, the tubes were dismantled for root quantification using the methods of Smucker et al. (1982). Samples were also collected for soil-water, $x$-ray absorption regression relationship development. X-ray absorption means and pixel standard deviation statistics for regions comprising the tubes were calculated and pixel histograms printed. Water content vs. time at each scanned depth was computed based on correlation at Day 84 using approaches in Tollner and Murphy (1990a).

Destructive testing is required to develop correlations between scanner outputs and root length measurements. To this end, eight pots were planted to soybean, Bahigrass and controls. The pots were maintained under similar conditions as were the large tubes. Each week two pots from each treatment were scanned, and the roots in the scanned plane were counted using techniques mentioned previously.

\section{Results and Discussion Mean absorption}

Over the 84-day test period, the rooting of both soybean and Bahiagrass plants extended to the maximum column depth when the root barrier was not pre ient (Figures 1a and 1b). The root barrier effectively stopped rooting activity. Root lengths above the biobarrier were not significantly $(P \leq 0.05)$ affected by the root barrier. 


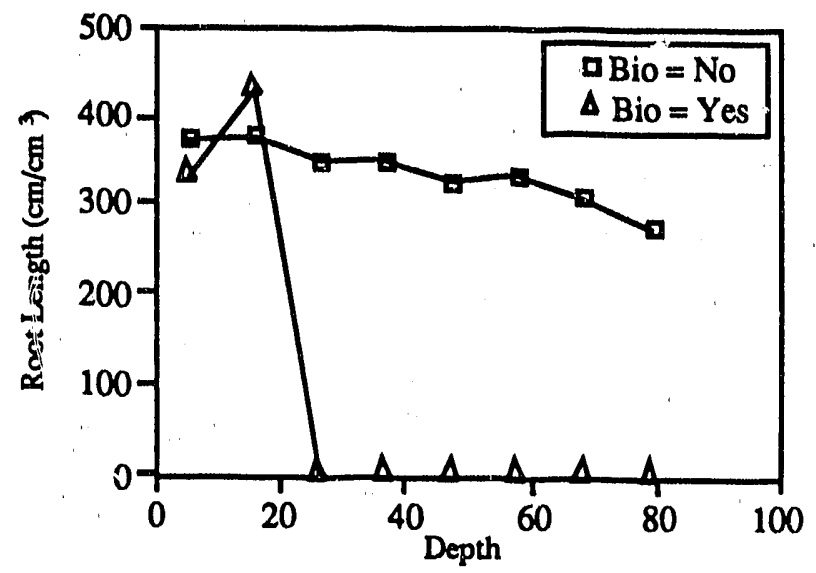

Figure 1a. Plot Showing Average for Three Reps of Root Length Density vs. Depth at Day 84 for Bahiagrass.

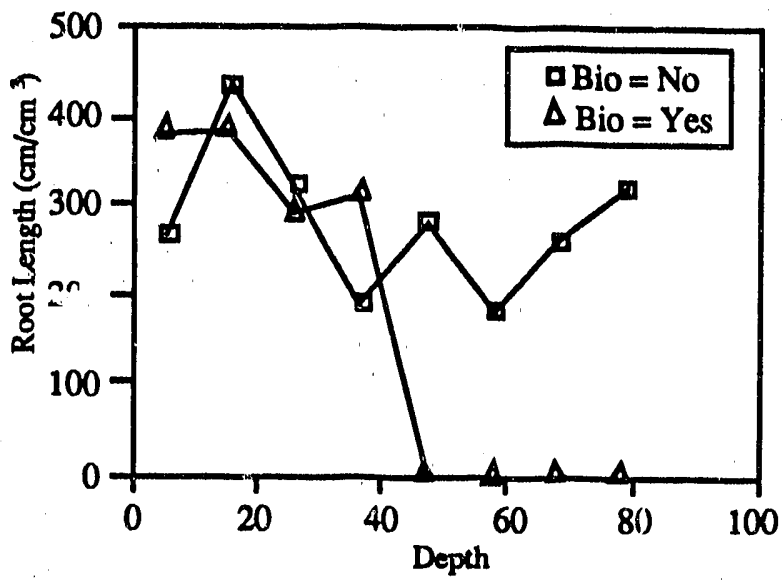

Figure 1b. Plot Showing Average for Three Reps of Root Length Density vs. Depth at Day 84 for Soybean.

The water content at Day 84 was predicted at the measured depths in each column using a calibration for Lakeland sand developed in Tollner et al. (1990a). A bulk density was first established for each measured depth increment at Day 0 using the calibration relationship with no water. The measured water content values were then calculated using the Day 0 density value. Predicted vs. observed water had an $\mathbf{R}^{2}=0.78$, with residual being normally distributed (NCSS, 1989). The initial bulk density at Day 0 varied by less than $5 \%$ of the whole column density vaine (1.39 $\left.\mathrm{MG} / \mathrm{m}^{3}\right)$. Figure 2.

X-ray CT images of the soybean at the uppermost depth were similar to that shown in

The soybean taproot was visible in the near-surface scan from Day $21 \mathrm{on}$. There was some indication of taproot visibility in the 2nd depth $(300 \mathrm{~mm}$ ) toward the end of the study (Day $60 \mathrm{on}$ ). Roots were not obvious at deeper levels in soybean or in any Bahiagrass images in any scan. This finding seems to reinforce findings in Tollyer et al. (1990b) that once the distance scale becomes as small as one or two pixels, measured contrast is much less than actual contrast, leading to difficulties in accurate detection. For example, absorption values for plant flesh approach those of 


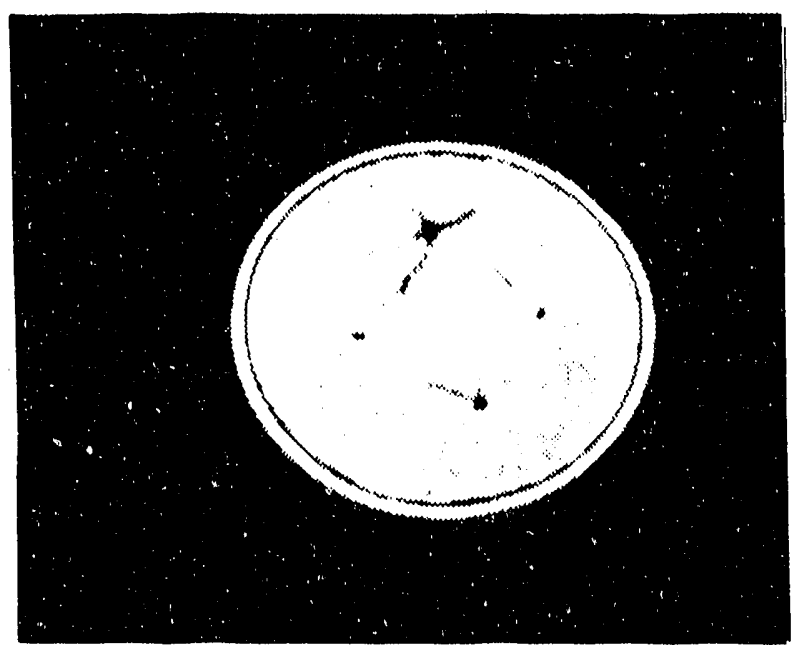

Figure 2. Photograph of CT Scan of Soybean at Day 57.

water $\left(0.191 \mathrm{~cm}^{-1}\right)$ when measured in regions with a radius of four or more pixels. With roots, the absorption is highly influenced by soil (soil values range from $0.28-0.34 \mathrm{~cm}^{-1}$ ). Values for roots sometimes approach $0.25 \mathrm{~cm}^{-1}$ values. In the absence of a priori knowledge of plant presence, the zones identified as roots in the soybean image would have been designated as lowdensity soils instead of roots or water. Development of the image features over time reinforced the hypothesis that the image features were indeed roots. Development of visible image features probably lagged behind actual root development of the soybean plants.

Plots of mean water content are shown in Figure 3, repres inting the controls. Three conditions, are indicated: no root barrier; root barrier as in soybzan; and root barrier as in Bahiagrass. The no root barrier condition is an average of two columns and the barriers as in soybean and Bahiagrass represent one column each. Mean absorption increased from Day 0 to Day 8 in response to water addition. At Depth 1, the root barrier as in Bahiagrass probably influenced the top-most depth reading because it seemed to cause a perched water table condition. (This is especially evident at Depth 2.) Depth 3 evidenced lower absorption with root barrier, due most likely to the barrier having broken suction levels when present. The barrier may also have impeded the flow of water. An analysis of variance was performed on the blank at each depth, pooling the two barrier conditions. The barrier caused significant differences at Depth 2 ( $\mathrm{P} \leq 0.05)$ and Depth 3 (P $\leq 0.1)$, but not at Depths 1 and 4 in the blank. Barrier-by-day interactions were significant $(\mathrm{P} \leq 0.05)$ at all depths.

Volumetric water in Bahiagrass vs. time for each four depths is shown in Figure 4. The barrier caused significantly higher water content at Depth $1(\mathrm{P} \leq 0.05)$ and Depth $2(\mathrm{P} \leq 0.05)$, but not at Depths 3 and 4 . The perturbation of the curve beyond Day 58 reflect the planned water stress events. With the barrier, there was no effect as expected at Depths 3 and 4 . At Depth 4, Bahiagrass did not display a significant difference $(\mathrm{P} \leq 0.05)$ compared to the blank, suggesting few roots or inactive roots at this time. Blanks were subjected to similar water stress treatment, but the effect is hardly noticeable. This indicated that the effect of water withdrawal by roots was evident in the Bahiagrass, particularly at Depth 3. Similar results for soybeans are shown in Figure 5. The root barrier caused significantly higher water content at Depth $2(\mathrm{P} \leq 0.10)$, Depth 3 ( $\mathrm{P} \leq 0.05)$ and Depth $4(\mathrm{P} \leq 0.01)$. Soybean without root barrier extracted water from Depths 3 and 4 as evidenced by the depressed water level without the barrier. Soybean with the barrier showed no response at Depths 3 and 4 as expected. The evidence of water extracted without root barrier and no water extracted with a barrier suggests the possibility of qualitative documentation of root presence with the CT scanner. 


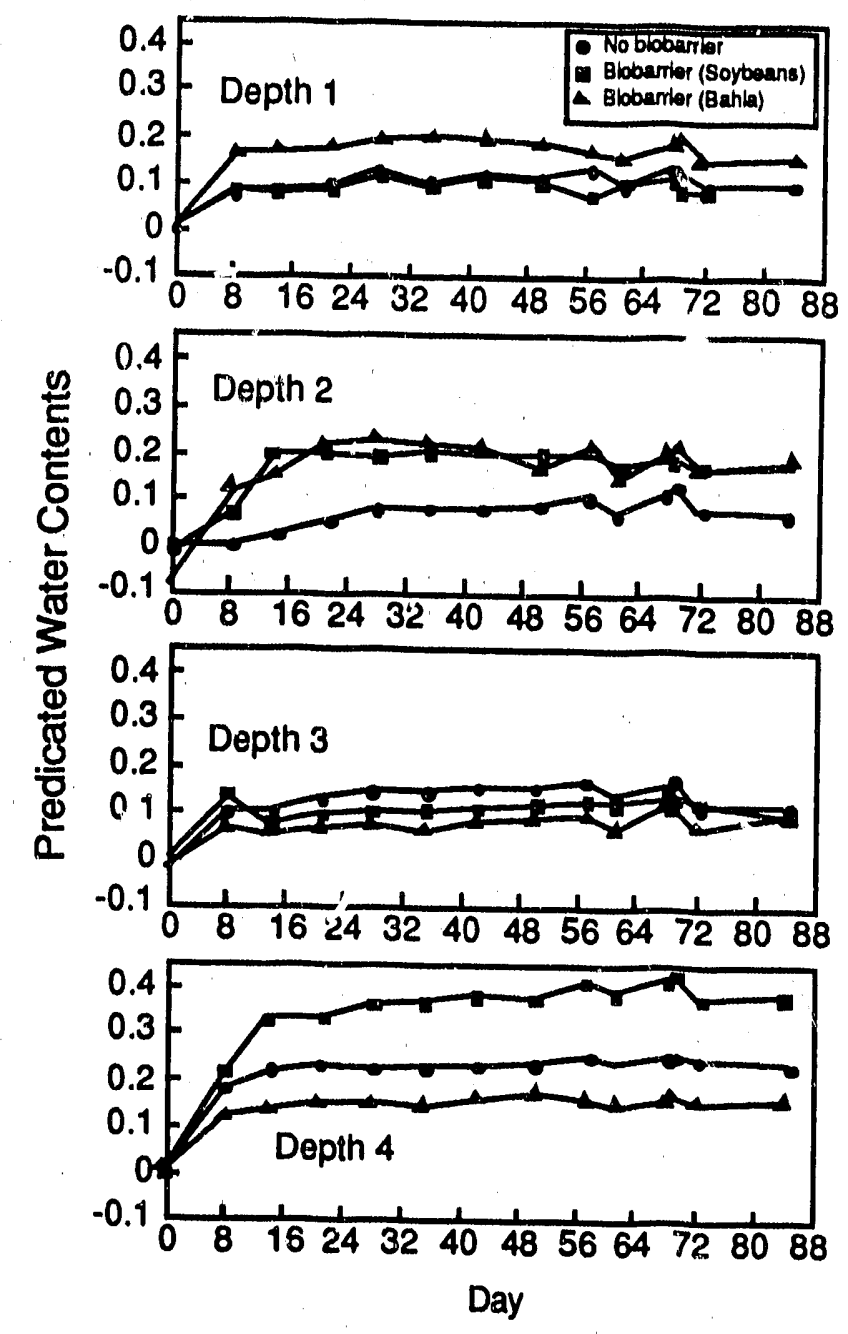

Figure 3. Plots of Predicted Volumetric Water Content vs.

Time for the Blank Controls.

The $\mathrm{x}$-ray mean absorption, the reflecting soil density (which was constant), and the water content change with time, can assess roots indirectly due to differences in water content. Further studies are needed, wherein the Richards' equation, with an appropriate root uptake term, could be used to further study root uptake and drainage from the tubes.

\section{Pixel standard deviation and absorption histograms}

A schematic diagram of a pixel histogram showing key features of the pixel absorption histogram is shown in Figure 6a. An actual histogram for Lakeland sand, soybeans, Depth 1, Day 57, is shown in Figure 6b. 


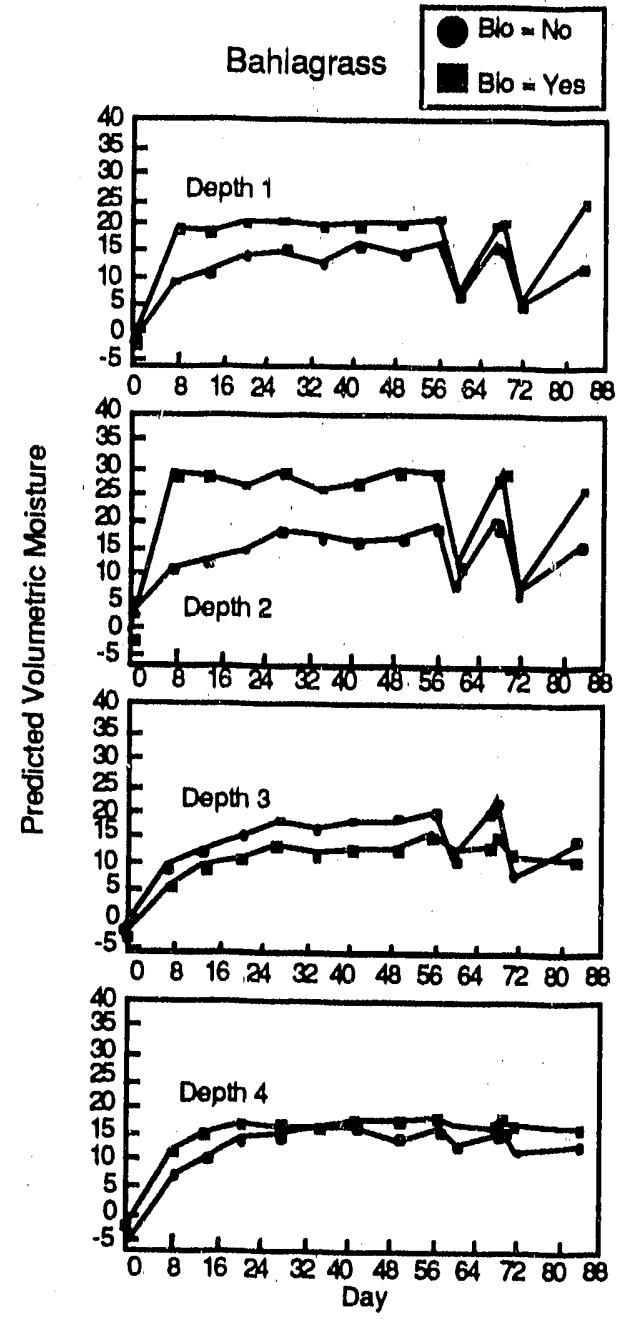

Figure 4. Plots of Predicted Volumetric Water Content vs. Time for the Bahiagrass

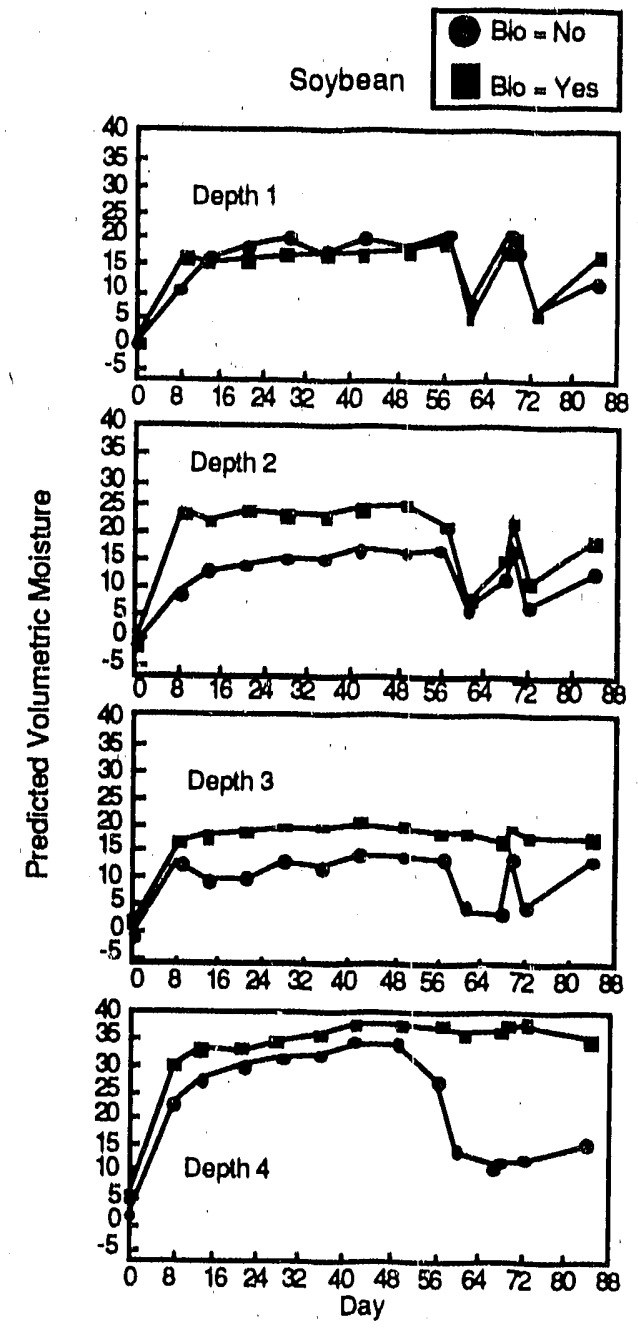

Figure 5. Plots of Predicted Volumetric Water Content vs. Time for the Soybean.

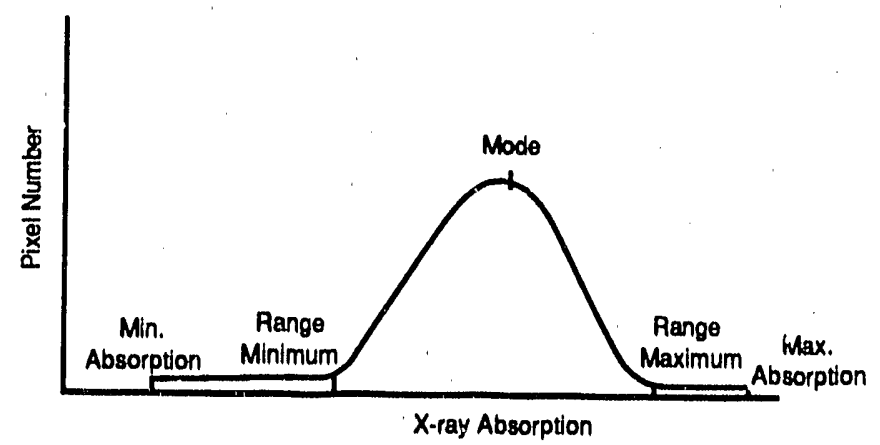

Figure 6a. Schematic Diagram of a Pixel Histogram Showing Several Variables Which were Defined to Characterize Histogram Features. X-Ray Absorption Values Less than the Range Minimum (RNGMI) or Greater than the Range Maximum (RNGMX) are Designated as Minimum and Maximum Outliers. 


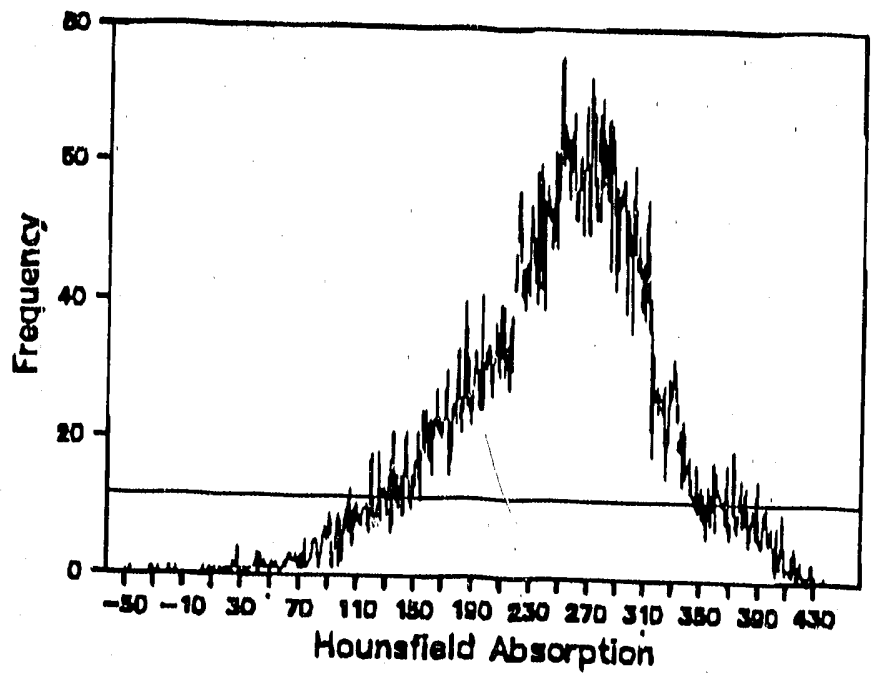

Figure 6b. Actual Pixed Histogram for Lakeland Sand, Soybeans, Depth 1, Day 57.

The vast majority of the pixels fell within the range maximum (RNGMAX) and the range minimum (RNGMIN). RNGMAX was defined in operational terms as the extreme absorption level possessed by at least two pixels. RNGMIN was defined to be the same distance from the mode on the other extreme. The spread between RNGMIN and RNGMAX was about three
standard deviations.

The maximum and rainimum absorption (MAX and MIN) is the respective maximum and minimum level of absorption observed in a given image. The correlation analysis, involving all tubes and depths, suggested high partial correlations between RNGMIN, RNGMAX and MAX always less than 0.4. The deterioration in vs. RNGMIN, vs. RNGMAX and vs. MAX, was affected histogram symmetry were occurring in the relationship betweenges over time which variables, particularly in the soybean tubes. MIN was well correlated between MIN and the other and histograms from the blanks were symmetric was well correlated to MAX in the blanks ( $r \geq 0.8$ ) some evidence of a departure from symmetric (e.g., having no "tail"). Bahiagrass tubes showed study.

In Figure 6a, the histogram can be construed to be representative of two symmetric distributions, one representing soil pores and roots and the other representing soil solids and water. As the pore and rooting component increased, one could expect a shift to develop between the overall mean and the mode (which is taken to represent the mean value of the soil and water
component. 
Techniques for interpreting the pixel standard deviation in Tollner et al. (1990b) could also be used to quantify the size of the pore and root component. Tollner et al. (1990b) presented the following relationships for describing the numbers of pixels in each of two subregions of a twocomponent image:

$$
S_{P}^{2}-S_{L}^{2}=\frac{1}{N-1} \sum_{L=1}^{L_{T}}\left(X_{L}-\bar{X}\right)^{2}+\frac{1}{n-1} \sum_{M=1}^{M_{T}^{T}}\left(X_{M}-\bar{X}\right)^{2}
$$

where

$$
\begin{aligned}
\mathrm{X}_{\mathrm{L}}= & \text { mean of soils (omponent (mode in Figure 6a) }\left(\mathrm{L}^{-1}\right), \\
\mathrm{X}_{\mathrm{M}}= & \text { mean of pore and root component }\left(\mathrm{L}^{-1}\right)(\text { could be estimated } \\
& \text { by taking a simple or arbitrary weighted average between } \\
& \text { RNGMIN and MIN), } \\
\mathrm{X}= & \text { overall image mean }\left(\mathrm{L}^{-1}\right), \\
\mathrm{S}_{\mathrm{P}}= & \text { overall pixel standard deviation }\left(\mathrm{L}^{-1}\right), \\
\mathrm{S}_{\mathrm{L}}= & \text { standard deviation of the soils component, } \\
\mathrm{L}_{\mathrm{T}}= & \text { number of pixels representing soils, } \\
\mathrm{M}_{\mathrm{T}}= & \text { number of pixels representing the pore and root componet, } \\
\mathrm{N}= & \text { total number of pixels in the image. }
\end{aligned}
$$

Also, $\quad \mathrm{M}_{\mathrm{T}}+\mathrm{L}_{\mathrm{T}}=\mathrm{N}$

With the growth of roots and the development of the pixel histogram minimum outlier zone, the pixel standard deviation should increase. The standard deviation statistics reflect some effect of water content as well as the tail effect; therefore, it is not uniquely influenced by the outlier zone growth. Hence, the variables DELMIN and MINPIX discussed above seem to be the most appropriate indicator of rooting development.

\section{Conclusions}

In a plant root development study involving the growth of soybean and Bahiagrass species in Lakeland sand columns with and without chemical rooting barrier, $x$-ray CT provided three types of output indicative of rooting activity. The first of these indicators $\mathrm{v}$. images of roots. However, the appearance of visible features probably lags the actual presence of plant root mass. The other two indicators were the effect on surrounding soil water content and selected statistics determined from pixel histograms.

$\mathrm{X}$-ray CT confirmed in a nondestructive manner $\mathrm{l}$ ' at the rooting barrier was effective in the case of soybeans and Bahiagrass based on obvious changes in water withuirawal patterns. Histogram symmetry also ajpeared to change over time.

\section{Acknowledgements}

The authors express appreciation to the Westinghouse Savannah River Company for support of this project. The data collection of Messrs. Stan Thain and Wayne O!sen are gratefully acknowledged. Thanks to Ms. Doris Walton for clerical assistance. 


\section{References}

Anderson, S. and S.J. Gantzler, "Determination of soil water content by $x$-ray computed tomography and NMR imaging," Proc. Int. Conf. on Measure of Soil and Plant Status 1,239-245, Logan, UT (1987).

Brown, J.M., W.C. Fonteno, D.K. Cassell and G.A. Johnson, "Computed tomographic analysis of water distribution in three porous foam media," SSSA Journal 51,1121-1125 (1987).

Hainsworth, J.M. and L.A.G. Aylmore, "Water extraction by a single plant root," SSSA Journal $50,41-45$ (1986).

NCSS, Number ci uncher statistical sysiem version 5.02: User's manual, NCSS, Kaysville, UT (1988).

Rogers, H.H. and P.A. Bottomley, "Insitu nuclear magnetic resonance imaging of roots: Influence of soil type, ferromagnetic particle content and soil water," Agron. J. 79,957-965 (1987).

Smucker, A.J.M., S.L. McBurney and A.K. Srivastava, "Quantitative separation of roots from compacted soil profiles by the hydropneumatic elustriation system," Agron. J. 74,500-503 (1982).

Tollner, E.W., J.W. Davis and B.P. Verma, "Managing errors with X-ray CT when measuring physical properties," TRANSACTIONS of the ASAE 32(3),1090-1096 (1989 b).

Tollner, E.W., R. Harrison and C. Murphy, "Interpreting the pixel standard deviation statistic in Xray computed tomography," TRANSACTIONS of the ASAE (In Review) (1990 b).

Tollrer, E.W. and C. Murphy,"Factors affecting the absorption of x-rays in soils with computed tomography," TRANSACTIONS of the ASAE (In Review) (1990 a).

Tollner, E.W., B.P. Verma and J.M. Cheshire,"Observing soil-tested interactions and soil organisms using computer tomography," TRANSACTIONS of the ASAE 30(6),1605-1610 (1987).

Tollner, E.W. and B.P. Verma,"X-ray CT for quantifying water content at points within a soil body," TRANSACTIONS of the ASAE 32(3),1040-1096 (1989). 
-END-

DATE FILMED

I 13 
